\title{
Guía bibliográfica para la historia de las islas Filipinas, 1565-1898*
}

\author{
Patricio Hidalgo Nuchera \\ Universidad Autónoma de Madrid \\ Félix Muradás García \\ Biblioteca Nacional de España
}

Bibliografía de bibliografías que recoge las obras de referencia (bibliografías, catálogos, diccionarios, enciclopedias, repertorios biográficos, etc.) que contienen información útil para los estudiosos de la historia de las Islas Filipinas durante el período hispánico, tanto aquéllas específicamente referentes a este archipiélago como las que le dedican un apartado dentro del contexto general del mundo hispánico.

Con la presente bibliografía de bibliografías pretendemos proporcionar a las personas interesadas en el estudio de las Filipinas una herramienta de trabajo consistente en la recopilación de todas las obras de referencia (bibliografías, tipobibliografías, catálogos, repertorios biográficos, diccionarios...) que puedan serles útiles. Dos han sido los límites autoimpuestos: uno cronológico, desde la conquista del archipiélago a su independencia de España; otro temático, enfocado a obras de carácter histórico, lo que implica haber dejado de lado obras de temática geográfica, ${ }^{1}$ artística, etc.

Todas las bibliografías de bibliografías recogidas se atienen exclusivamente a las Filipinas, a excepción de la de Hilton y Labandeira de 1983, que también toca a Hispanoamérica. ${ }^{2}$ De especial importancia, por ser una obra periódica que actualiza la información, es la revista Philippine

* Una versión anterior de este trabajo fue presentada al V Congreso Internacional de la Asociación Española de Estudios del Pacífico "España y el Pacífico. Construcción de imperios, construcción de naciones", celebrado en Madrid del 15 al 19 de noviembre de 1999. La visita posterior a la Biblioteca del Congreso (Washington, D.C.) el mes de agosto de 2000 nos ha permitido revisar y aumentar el número de referencias.

1 Pelzer, Karl J. Selected bibliography on the Geography of Southeast Asia. New Haven, Conn.: Yale University Southeast Asia Studies, 1948-1971. 3 v. (Monograph Series; 7). Vol. II: Philippines (1950). 76 pp. Posterior es la de Huke, Robert E. Bibliography of Philippine Geography, 1940-1963. A Selected List. Hanover, New Hampshire: Dartmouth College, Dept. of Geography, 1964. 84 pp. (Geography Publications at Dartmouth; 1). Reimpreso en Millwood, N.Y.: Kraus Reprint, 1980.

2 Sylvia L. Hilton y Amancio Labandeira, Bibliografía hispano-americana y filipina. Madrid: Fundación Universitaria Española, 1983. 411 pp. (Biblioteca Histórica Hispanoamericana; 6). 
National Bibliography, publicada desde 1974 por la Biblioteca Nacional de

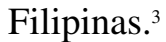

En cuanto a las bibliografías, y como hemos dicho antes, nos hemos limitado a las obras enfocadas a la Historia o que puedan ser útiles al estudio de ésta. En cualquier caso, la tipología es bastante amplia: así, las hay generales, locales, misioneras, económicas... Y aunque tentados en principio a confeccionar epígrafes atendiendo a los distintos tipos existentes, no lo hemos tenido por conveniente debido a las escasas referencias recogidas sobre algunos de ellos. Por otra parte, hemos incluido una serie de obras generales que contienen información relevante sobre las Filipinas, como son las de Palau, Sánchez Alonso, Polgar o Simón Díaz. ${ }^{4}$ No queremos dejar de recordar aquí la crítica que Retana y Gamboa formuló en 1906 a las bibliografías y tipobibliografías filipinas existentes hasta entonces: ${ }^{5}$ mientras alababa las de Medina ${ }^{6}$ y las suyas propias, censuraba sañudamente otras, en particular las de Pardo de Tavera y la de los agustinos Pérez y Güelmes.

El segundo epígrafe de este trabajo lo ocupan las tipobibliografías, o sea, aquellas bibliografías que recogen las obras publicadas o impresas en un determinado lugar. Merecen mención especial las clásicas de J.T. Medina y W.E. Retana. De las citadas por nosotros, observamos que las hay tanto generales a todas las Islas como específicas a un lugar particular, algunas son relativas a un instituto religioso, en concreto al franciscano, e incluso hay una referente a un tipo específico de materiales, como son los incunables. Como es propio de las tipobibliografías, muchas de las obras recogidas en ellas no tratan sólo de Filipinas; pero al incluir los trabajos de carácter histórico publicados en distintos lugares del archipiélago, resultan repertorios imprescindibles que nos proporcionan, además, un panorama de la situación cultural de las Islas en cada época.

En el apartado tercero se recogen los catálogos impresos de fondos bibliográficos ${ }^{7}$ sobre Filipinas propiedad de diversas instituciones cultura-

3 Se recibe en la Biblioteca Nacional de España, Madrid, sign. D/8500.

4 En cambio, y debido a que su utilidad nos parece bastante escasa, no hemos incluido las obras de León Pinelo y de Nicolás Antonio.

5 En el prólogo a su obra Aparato bibliográfico de la Historia General de Filipinas deducido de la colección que posee en Barcelona la Compañía General de Tabacos de dichas islas. Madrid: Minuesa de los Ríos, 1906. 3 v. Vid. tomo I, pp. III-X.

6 Sobre este autor, vid. Roberto Ramos, Bibliografía de Don José Toribio Medina. México: Gráficas Herber, 1953. 44 pp.

7 Dejamos totalmente de lado los fondos manuscritos. Sobre los conservados en España, vid. Patricio Hidalgo Nuchera, Guía de fuentes manuscritas para la historia de Filipinas conservadas en España. Con una guía de instrumentos bibliográficos y de investigación. Madrid: Fundación Histórica Tavera; Fundación Santiago, 1998. XV, 496 pp. 8 h. (Philippine Centennial Project). 
les, así públicas como privadas, ${ }^{8}$ la mayoría existentes hoy día, pero otras ya no. La ordenación ha sido realizada por países — por razones obvias, éstos son España, EEUU, Filipinas y Japón- y, dentro de cada uno de ellos, por ciudades.

Entre las bibliotecas hoy dispersadas, hay que destacar la del MuseoBiblioteca de Ultramar. Fue creada por real decreto de 17 de octubre de 1887 con ocasión de la celebración en Madrid — desde el 30 de junio anterior - de una exposición de productos de las Islas Filipinas. Sus fondos, referentes a la historia de los países hispánicos en general, procedían de la biblioteca del Ministerio de Ultramar, de quien dependía, a los que se añadieron donativos y adquisiciones, entre los que hay que destacar las obras y documentos americanistas de Pascual Gayangos y Justo Zaragoza. Aunque suprimido el citado Ministerio en 1899 al perderse las últimas posesiones españolas, la Biblioteca siguió funcionando, en incluso en 1900 se publicó su catálogo. ${ }^{9}$ Sin embargo, la falta de fondos económicos hizo que finalmente se cerrara y pasara a la Biblioteca Nacional de Madrid. De los fondos aquí llegados ${ }^{10}$ unos pasaron a la sección de Manuscritos y, otros, a la de Raros; el resto pasó a la sección de Hispanoamérica cuando ésta se creó en 1949. Posteriormente, en 1983 se realizó un expurgo de esta

8 Hay que tener en cuenta que no todas las instituciones que atesoran fondos bibliográficos filipinos tienen catálogos impresos de ellos; sin embargo, pueden fácilmente localizarse in situ por medio de ficheros, instrumentos de descripción interna e incluso, en algunas, de sistemas informáticos. Entre las instituciones públicas cabe citar la Biblioteca Hispánica (dependiente de la AECI, en Madrid), el Centro de Estudios Históricos del CSIC, en Madrid, y la Escuela de Estudios Hispanoamericanos (también del CSIC, pero en Sevilla); de entre las privadas, la biblioteca del Colegio de los Agustinos Filipinos (Valladolid), la del convento de San Pedro Mártir que los PP. dominicos de la provincia del Santo Rosario poseen en Alcobendas (Madrid) y la del Archivo Franciscano Ibero-Oriental (Madrid). Para una lista de instituciones que guardan materiales impresos filipinos, vid. los trabajos de Marina G. Dayrit, "The Availability of Filipiniana Materials in Foreign Libraries and Archives". Journal of Philippine Librarianship I:1 (Diliman, Quezon City, University of the Philippines, Institute of Library Service, March 1968): pp. 7-30; y Directory of Libraries in the Philippines. Quezon City: University of the Philippines Library, 1973. $131 \mathrm{pp}$.

9 Catálogo de la Biblioteca de Ultramar. Madrid: Imprenta sucesora de M. Misuesa de los Ríos, 1900. 350 pp. Aunque la obra es anónima, su autor fue Francisco P. Vigil. Aparte de las obras filipinas incluidas dentro del corpus principal, este catálogo recoge en sendos apéndices publicaciones periódicas filipinas y obras en leguas indígenas. Sobre esta colección, vid. Antonio García Llansó, El Museo-Biblioteca de Ultramar. Barcelona: Tipolitografía de Luis Tasso, 1897. 87 pp.; y Luisa Cuesta, "Dos grandes bibliotecas del Extremo Oriente para la Nacional de Madrid". Boletín de la Dirección General de Archivos y Bibliotecas 51 (Madrid, julio-septiembre 1959): pp. 13-14.

10 Decimos esto porque la colección no recaló íntegra en la Biblioteca Nacional. Un lote de 856 obras llegó al Museo de América — creado por Real Decreto 18 abril 1941—, de las cuales casi 150 son relativas a las Filipinas. Sobre estos fondos, vid. Mariano Cuesta Domingo y Nieves Sáenz Gracia, "Fondos de la Biblioteca de Ultramar en el Museo de América". Historiografía y Bibliografía Americanista 24 (Sevilla, CSIC, 1980): pp. 127-187. 
última sección, consistente en pasar las obras anteriores a 1800 a Raros y las publicaciones periódicas a la sección de Revistas. Por último, al desaparecer la sección de Hispanoamérica —oficialmente en 1986, pero en la práctica en 1992 - lo que quedaba pasó al Depósito general, consultable en el salón general de lectura.

El siglo XIX fue pródigo en coleccionistas de libros filipinos. Retana cita $^{11}$ los nombres de fray Agustín María de Castro, Francisco Zapater, ${ }^{12}$ José de Keyser y Muñoz, Vicente Barrantes, ${ }^{13}$ Juan Alvarez Guerra, Ferdinand Blumentritt, ${ }^{14}$ Trinidad H. Pardo de Tavera, ${ }^{15}$ José Velarde, ${ }^{16}$ el agustino Eduardo Navarro, ${ }^{17}$ Edward E. Ayer, ${ }^{18}$ Epifanio de los Santos. Pero de otros dos hay que hacer una especial mención. Uno fue Antonio Graíño, quien reunió una colección de libros espléndida tanto por la cantidad como por la calidad de sus rarezas bibliógraficas. Fallecido en 1945, su colección fue comprada por el Estado español en 1957, el cual la dividió en dos partes: una, fundamentalmente de libros sobre América, entre los cuales había un lote importante de gramáticas, diccionarios y obras en lenguas indígenas, fue llevada a la biblioteca del entonces Instituto de Cultura Hispánica;

11 En el prólogo a su obra Aparato bibliográfico de la Historia General de Filipinas..., tomo I, pp. XXXV-XXXVI.

12 Muchas de sus obras pasaron a la colección de Retana y, posteriormente, a la biblioteca de la Compañía General de Tabacos de Filipinas. Vid. Retana en el prólogo a su obra Aparato bibliográfico de la Historia General de Filipinas..., tomo I, p. XXXV.

13 A su muerte, su familia enajenó la biblioteca a D. Pedro Vindel, quien después la vendió. Parte la compró el bibliógrafo norteamericano Edward E. Ayer; otra lo fue por la Compañía General de Tabacos de Filipinas. Vid. Retana en el prólogo a su obra Aparato bibliográfico de la Historia General de Filipinas..., tomo I, pp. XXXV s.

14 Sobre este autor, vid. Vida y obras de Fernando Blumentritt. Folleto preparado por la Secretaría de la Asamblea filipina. Manila: Bureau of Printing, 1914. 85 pp.

15 En 1903 publicó el catálogo de su biblioteca: Biblioteca filipina. Washington: Government Printing Office, 1903. 439 pp. Hoy día la biblioteca está en poder de sus herederos. Hay una colección Pardo de Tavera en la Biblioteca Nacional de Manila (se cree que parte de la colección se perdió durante la II Guerra Mundial), aunque parece ser un duplicado de la colección original. Vid. al respecto, Vicente S. Hernández, History of books and libraries in the Philippines, 1521-1900: a study of the sources and chronology of events pertaining to Philippine library history from the sixteenth to the end of the nineteenth century. Manila: The National Comission for Culture and Arts, 1996. XVI, 248 pp.; p. 101. Sobre este autor, vid. Eloísa G. Abelarde, "Trinidad Hermenegildo Pardo de Tavera”. Journal of Philippine Librarianship II:1-2 (Diliman, Quezon City, University of the Philippines, Institute of Library Service, March-Sept. 1969): pp. 45-53.

$16 \mathrm{Su}$ colección fue adquirida en 1964 por la antigua biblioteca del Instituto de Cultura Hispánica, hoy Biblioteca Hispánica, dependiente orgánicamente de la Agencia Española de Cooperación Internacional (AECI). Vid. M. ${ }^{\mathrm{a}}$ Isabel Morales Vallespín, Alicia Girón García y Elena M. ${ }^{\mathrm{a}}$ Santiago Páez, Nueva guía de las bibliotecas de Madrid. Madrid: Asociación Nacional de Archiveros, Arqueólogos y Documentalistas (ANABAD), 1979; p. 232.

17 Sus libros están en el Colegio de los Agustinos Filipinos, en Valladolid. 
la otra, compuesta principalmente de obras sobre Filipinas, pero también sobre Cuba y Puerto Rico, fue depositada en la Biblioteca Nacional de España. Posteriormente se realizó el catálogo de los libros filipinos de dicha colección. ${ }^{19}$

Pero, sin duda, el gran coleccionista de libros filipinos fue Wenceslao Emilio Retana y Gamboa (1862-1924). ${ }^{20}$ Funcionario y periodista, reunió una extraordinaria colección que, en 1900, vendió a la Compañía General de Tabacos de Filipinas. Esta institución, creada en Barcelona el 26 de noviembre de 1881 con el objetivo de explotar el tabaco filipino, dedicó, sin embargo, parte de sus esfuerzos a la actividad cultural, en la que destaca la creación de una extraordinaria biblioteca de temas filipinos. ${ }^{21}$ Comenzada en 1883 con miras exclusivamente prácticas, es decir, para que la Compañía pudiera disponer de la información que su actividad en el Archipiélago requería, la curiosidad bibliográfica del entonces vicedirector y luego director de la Compañía, Clemente Miralles de Imperial, hizo que se comprara todo lo relativo a las Filipinas. Ello llevó a que en 1894 se entablaran relaciones bibliográficas con Retana y Gamboa, quien seis años más tarde accedió a vender a la firma barcelonesa su propia colección, que

18 Sus libros se conservan en la Colección Ayer, depositada en la Newberry Library, perteneciente a la Universidad de Chicago, Illinois, EEUU. Mr. Ayer ordenó a sus agentes comprar materiales filipinos tan pronto como la victoria norteamericana en la bahía de Manila (1 mayo 1898) fue cablegrafiada a EEUU. Robertson usó esta colección para la compilación de su obra The Philippine Islands (los papeles de Robertson están ahora en la Duke University, Durham, North Carolina, Philippine Studies Program). Ayer, miembro de la junta directiva de la Newberry Library de Chicago, donó su colección a esta biblioteca en 1911. Vid. al respecto, Hernández, History of books and libraries in the Philippines, $1521-1900 \ldots$, p. 86.

19 Carlos Sanz López. Bibliografía descriptiva y crítica de los libros filipinos de Don Antonio Graíño. Manila: Instituto Nacional de Historia, 1976. 300 pp. Sobre esta colección, vid. Luisa Cuesta, "Dos grandes bibliotecas del Extremo Oriente para la Nacional de Madrid". Boletín de la Dirección General de Archivos y Bibliotecas 51 (Madrid, julio-septiembre 1959): pp. 13-14.

20 Para una biografía de Retana, vid.: Manuel Artigas y Cuerva, Quién es Retana. Su antaño y hogaño; reseña bio-bibliográfica. Reimpreso de la Revista Biblioteca Nacional Filipina. Manila: Imprenta y Litografía de Juan Fajardo, 1911. Epifanio de los Santos Cristóbal, Wenceslao E. Retana. Ensayo acerca de este ilustre filipinista. Madrid: 1909. John N. Schumacher (SJ), "Wenceslao E. Retana: An Historiographical Study". Philippine Studies X:4 (Manila, 1967): pp. 550-576. Pueden consultarse también los tres estudios de Antonio Caulín Martínez: "Wenceslao E. Retana y la Historia de Filipinas". Espacio, Tiempo y Forma (Serie V, Historia Contemporánea) 6 (Madrid, UNED, 1993): pp. 419-440. "Retana y la bibliografía filipina 1800-1872: El Aparato bibliográfico como fuente para la historia de Filipinas. (1. a parte: fuentes generales)". Revista Española del Pacífico 4 (Madrid, 1994): pp. 85-104. "Retana y la bibliografía filipina 1800-1872: El Aparato bibliográfico como fuente para la historia de Filipinas. (2. parte: fuentes específicas)". Revista Española del Pacífico 6 (Madrid, 1996): pp. 187-210.

21 Sobre las actividades culturales de la Compañía, vid. Hidalgo Nuchera, Guía de fuentes manuscritas para la historia de Filipinas conservadas en España..., pp. 92-94. 
contenía entonces 2.697 títulos. ${ }^{22}$ Cuatro años más tarde, la biblioteca de la Compañía, dirigida por José Sánchez Garrigós, aumentó considerablemente su tamaño con la compra de lo mejor que el librero madrileño Pedro Vindel ofrecía en su Catálogo sistemático e ilustrado de la Biblioteca Filipina puesta en venta por Vindel (Madrid, 1904).

El contenido de la magnífica biblioteca organizada por la Compañía en Barcelona es conocido gracias a la publicación de su catálogo, ${ }^{23}$ en cuyos tres volúmenes Retana describe 4.623 impresos de tema filipino, ordenados cronológicamente - excepto el periodismo, que va al final del tercer tomo- y con anotaciones críticas. Todas las piezas llevaban el ex-libris de la Compañía, de estilo modernista, obra del catalán José Triado y Mallol.

Debido a las necesidades económicas por las que pasaba, la Compañía General de Tabacos decidió vender su biblioteca. En 1912 el director de la Philippine Library de Manila, James Robertson, concertó su adquisición por el Gobierno filipino con el fin de destinarla a dicha institución. La compra fue aprobada por ley de 3 de febrero de 1913 en la cantidad de 200.000 pesos. El primero de julio de ese mismo año ya estaban los libros en Manila. En 1929 la Philippine Library fue instalada en la planta baja del palacio de la Asamblea Filipina, donde a consecuencia de la batalla de Manila (1945) fue casi enteramente destruida. Así, pues, de la antigua biblioteca filipina de la Compañía General de Tabacos no queda hoy otro recuerdo, salvo la pequeña fracción que se salvó, que el de su monumental catálogo publicado en 1906.

No podemos dejar de mencionar en este lugar a Pedro Vindel y a Carlos Sanz. En cuanto al primero, bien es cierto que no fue un coleccionista, sino un librero-anticuario, del cual recogemos diversos catálogos de libros filipinos puestos en venta. Un doble motivo nos lleva a citarlo: por un lado, su fondo se nutrió precisamente de las bibliotecas de algunos

22 Vid. al respecto los dos catálogos que el propio Retana había publicado de su biblioteca. El primero, Catálogo de la biblioteca filipina de W.E. Retana (Madrid, 1893) y, el segundo, Catálogo abreviado de la biblioteca filipina de W.E. Retana (Madrid, 1898). Los duplicados que, gracias a esta compra, contenía la biblioteca de la Compañía fueron cedidos al propio Retana, quien a su vez los puso en venta. Vid. al respecto el Catálogo de las obras filipinas que ofrece en venta W.E. Retana. Barcelona: 1902.

23 Wenceslao Emilio Retana. Aparato bibliográfico de la Historia General de Filipinas, deducido de la colección que posee en Barcelona la Compañía General de Tabacos de dichas Islas. Madrid: Minuesa de los Ríos, 1906. 3 v. Tomo I, años 1524-1800. Tomo II, años 1801-1886. Tomo III, años $1887-$ 1905. Los tres volúmenes tienen un total de 1800 páginas en cuarto mayor. La tirada fue de 315 ejemplares. Como el propio Retana señala en el prólogo (tomo I, p. XLIV), esta obra no es un simple inventario de una biblioteca, sino que en sus páginas se contiene la referencia de todos los elementos que son precisos para escribir la Historia general de Filipinas, de ahí el título que a la obra he puesto... 
coleccionistas; y, a la vez, nutrió otras bibliotecas, como la de la Compañía General de Tabacos, que le compró una gran cantidad de libros filipinos en $1904 .{ }^{24}$ En cuanto a Sanz López, fue un generoso editor de numerosos mapas y documentos antiguos referentes a la historia de los descubrimientos geográficos, entre ellos el de Filipinas. Su fallecimiento en enero de 1979 le impidió culminar una Bibliografía general en tablas sinópticas de las Islas Filipinas, cuyas más de cuatro mil fichas deben encontrarse en la Casa-Museo de Colón en Valladolid, institución a la que en marzo de 1970 donó todos sus libros y papeles de trabajo..$^{25}$

Como importantes obras de referencia, recogemos una serie de repertorios biográficos, diccionarios temáticos y enciclopedias. En cuanto a los primeros, y aparte de los específicamente referidos a personajes vinculados a la historia de Filipinas, hemos creído conveniente citar el que sin duda es el más completo para el mundo hispánico: nos referimos al conocido en la jerga bibliográfica como ABEPI - Archivo biográfico de España, Portugal e Iberoamérica - . Por otra parte, no es de extrañar que, debido al relevante papel que jugaron las órdenes religiosas en la colonización del archipiélago, sean mayoría los títulos relativos a personas eclesiásticas, aunque también los hay de ingenieros militares, conquistadores, nobles, etc. En cuanto a los diccionarios y enciclopedias, no cabe duda que pueden desempeñar un papel muy útil en la investigación histórica. Como puede observarse en la lista que ofrecemos, su temática es variada, pues los hay relativos a la Administración, genealógicos, histórico-culturales, etnográficos, geográficos, mitológicos e incluso de idiomas.

Por último, somos conscientes de que la variedad de lenguas existentes en Filipinas durante la época colonial - tagalo, pampango, ilocano, visaya, etc. - puede conducir a la necesidad práctica de traducir algunos términos nativos o bien suscitar el interés, no sólo lingüístico sino también

24 En la "Advertencia" al tomo I de su Biblioteca Oriental. Comprende 2.747 obras relativas a Filipinas, Japón, China y otras partes de Asia y Oceanía. Madrid: P. Vindel, Librero-Anticuario, 1911. 436 pp. (Catálogo de la librería de P. Vindel; 4), Vindel confiesa que Las obras que constituyen esta biblioteca proceden de las extinguidas de D. V. Barrantes, D.J.T. Medina, de Chile; Cánovas del Castillo, D. Justo Zaragoza, Fr. Eduardo Navarro y otros afamados bibliófilos... El número de libros relativos a Oriente, que hoy ofrecemos, no ha sido nunca puesto a la venta en tan crecida cifra... La Compañía General de Tabacos de Filipinas, establecida en Barcelona, reunió un buen número de manuscritos antiguos, y mediante un cambio por impresos que no poseía, me los cedió todo en junto, la mayoría de los cuales conservo, y de entre ellos he escogido casi todos los que ofrezco, desde los números 2.728 a 2.747.

25 Ramón Ezquerra, “In Memoriam: Carlos Sanz”. Revista de Indias, año XL, n. ${ }^{\text {1 }}$ 159-162 (Madrid, CSIC, enero-diciembre 1980): pp. 441-466. La cita de su obra inconclusa e inédita, en p. 460. 
histórico, por conocer los problemas de comunicación a los que tuvieron que enfrentarse los misioneros y la forma como éstos les hicieron frente (redacción de vocabularios y gramáticas). ${ }^{26}$ Ello justifica la sexta y postrera sección que cierra este trabajo, la bibliografía lingüística. Aparte de las obras bibliográficas ahí recogidas, hemos querido citar el diccionario de filipinismos de Retana y Gamboa, el de hispanismos en el tagalo de Cuadrado Muñiz y el bilingüe tagalo-español/español-tagalo de Serrano Lacktaw, éste último reeditado en Madrid el año 1965 por el Instituto de Cultura Hispánica. Sirva esta mínima selección de simple botón de muestra del amplio número de diccionarios lingüísticos existentes y que no podemos acopiar por desbordar el marco temático del presente trabajo. ${ }^{27}$

26 Un buen elenco de ellas son citadas por Antonio Quilis en su introducción a la reedición del Arte y regla de la lengua tagala de Fray Francisco de San José, OP (1610). Madrid: Ediciones de Cultura Hispánica, 1997. 90 pp. más ed. facsimilar; y por Cayetano Sánchez (OFM) en su introducción a la reedición del Vocabulario de lengua tagala, de Fray Pedro de San Buenaventura, OFM (1613). Valencia: Librerías "París-Valencia", 1994. 5 h. 707 pp. Para los problemas lingüísticos de los misioneros del archipiélago magallánico, vid. John L. Phelan, "Philippine Linguistics and Spanish Missionaires, 1565-1700”. Mid-America Historical Review XXXVII:3 (Chicago, Loyola University, July 1955): pp. 153-170.

27 Para una mayor información, vid. al respecto, Pilar Cruz García y Mauro García, "A List of Dictionaries, Vocabularies and Phrase Books in Tagalog and Other Philippine Languages". The Philippine Colophon II (Manila, Philippine Booklovers Society, October-December 1964): pp. 36-42; y Victor P. Gendrano, "Guide to Philippine Dictionaries". Jornal of Philippine Librarianship 3 (Diliman, Quezon City, University of the Philippines, Institute of Library Service, 1970): pp. 73-82. 


\section{Índice}

\section{Repertorios bibliográficos}

\subsection{Bibliografías de bibliografías}

BERNARDO, Gabriel A. Bibliography of Philippine Bibliographies: 1593-1961. Compiled by [...]; edited by Natividad P. Verzosa. Quezon City: The Ateneo de Manila University, 1968. XIV, 192 pp. (Occasional Papers of the Department of History. Bibliographical Series; 2).

FERNÁNDEZ, Emma J. Bibliografías filipinas en bibliotecas madrileñas. Tesis mecanografiada presentada al III Curso hispano-filipino. Madrid: 19641965. $2 \mathrm{v}$.

GENDRANO, Victor P. "Philippine Biographical Reference Materials". Journal of Philippine Librarianship I:2 (Diliman, Quezon City, University of the Philippines, Institute of Library Science, September 1968): pp. 44-53.

HART, Donn Vorhis. An Annotated Bibliography of Philippine Bibliographies: 1965-1974. Detroit, Michigan: Nothern Illinois University, Center for Southeast Asian Studies, 1974. 160 pp. (Occasional Papers; 4).

HILTON, Sylvia L. y Amancio LABANDEIRA. Bibliografía hispano-americana y filipina. Madrid: Fundación Universitaria Española, 1983. 411 pp. (Biblioteca Histórica Hispanoamericana; 6).

HOUSTON, Charles O. Jr. Philippine Bibliography: 1. An Annotated Bibliography of Philippine Bibliographies (since 1900). Manila: The University of Manila, 1960. 69 pp., 21 pp.

NOON, G. Raymond. Asia: Reference Works. A Selected Annotated Guide. London: Mansell, 1980. XVI, 365 pp. Para Filipinas, pp. 123-142. Una 1. edición, bajo el título de Asia: A Selected and Annotated Guide to Reference Works, fue publicada en Cambridge, Mass.; London, England: The Massachusetts Institute of Technology, 1971. XIII, 223 pp.; para Filipinas, pp. 84-96.

ORBASE, Lily O. Bibliography of Philippine Bibliographies, 1986-1993. Manila: The National Library of the Philippines, Bibliography Division, 1993, V, 27 pp.

- y Yolanda E. JACINTO (comps.). Bibliography of Philippine Bibliographies, 1962-1985. Manila: The National Library of the Philippines, Bibliography Division, 1987. V, 128 pp. 
SAITO, Shiro. The Philippines: A Review of Bibliographies. Honolulu, Hawaii: University of Honolulu, East-West Center, East-West Center Library, 1966. V, 80 pp. (Occasional Papers; 5).

\subsection{Bibliografías}

ABAD PÉREZ, Antolín (OFM). "Bibliografía misional hispánica en Filipinas". Missionalia Hispanica, año XXXIII, n. ${ }^{\circ} 97-99$ (Madrid, CSIC, 1976): pp. 279-290.

- "La bibliografía hispano-filipina y la aportación extremeña". En: Fr. Sebastián García, OFM. Extremadura en la evangelización del Nuevo Mundo. Actas y Estudios. Congreso celebrado en Guadalupe durante los días 24 al 29 de octubre de 1988. Madrid: Turner-Quinto Centenario-Junta de Extremadura, 1990: pp. 471-493.

ABRERA, Josefina B. (comp.). An Annotated Bibliography of the History of the Sugar Industry in Panay and Negros. Manila: The National Library of the Philipppines-The Ateneo de Manila University Press, 1963. 143 pp. (The Bibliographical Series; 1).

AGCAOILI, Cándida C. y Leticia A. ESPINAS. "Preliminary selective bibliography on the Christianization of the Philippines". Philippine Colophon III:1-2 (Manila, Philippine Booklovers Society, Jan-June 1965): pp. 2-17.

ANTONIO, Celia M. y Allen TAN. A Preliminary Bibliography of Philippine Cultural Minorities. Quezon City: Commission on National Integration, 1967. 34 pp. map.

BARADI, Edita R. Southeast Asian Research Tools. The Philippines. Honolulu, Hawaii: University of Hawaii, Asian Studies Program, Southeast Asian Studies, 1979. X, 304 pp. (South East Asia Paper; 16, Part V).

BERNARDO, Gabriel A. A Critical and Annotated Bibliography of Philippine, Indonesian and Other Malayan Folk-lore. Edited by Francisco Demetrio y Radaza, SJ. Cagayán de Oro City: Xavier University, 1972. 150 pp.

BERNARDO, Gabriel A. y Natividad P. VERZOSA. Philippine Retrospective National Bibliography: 1523-1699. Compiled by [...]; edited by John N. Schumacher, SJ. Quezon City: The National Library of the Philippines-The Ateneo de Manila University Press, 1974. XVI, 160 pp. (Occasional Papers of Department of History, Ateneo de Manila Bibliographical Series; 3).

BIBLIOGRAFÍA española sobre Filipinas. Madrid: Ministerio de Asuntos Exteriores, Dirección General de Relaciones Culturales, [1971]. 24 pp.

BLAIR, Emma Helen y James Alexander ROBERTSON (eds.). The Philippine Islands, 1493-1898: Explorations by early navigators, descriptions of the Islands and their people and records of the catholic missions, as related in 
contemporaneous books and manuscripts, showing the political, economic, commercial and religious conditions of those Islands from their earliest relations with european nations to the close of the nineteenth century. Translated from the originals. Edited and anotated by [... and ...], with historical introduction and additional notes by Edward Gaylord Bourne. With maps, portraits and other illustrations. Cleveland, Ohio: The Arthur H. Clark Co., 1903-1909. 55 v. ${ }^{28}$ Vol. LIII: Bibliography. 433 pp..$^{29}$

BLUMENTRITT, Ferdinand. Bibliotheca Philippina. Leipiz?: 1882-1885.

BUREAU OF PUBLIC LIBRARIES. Manuel L. Quezon: A Bio-bibliography. Compiled by the Research and Bibliography Division of the Public Library. Manila: Bureau of Public Libraries, 1962. 170 pp.

BUTENGKO, Helen. "Bibliography of Etnographic Titles relating to the Philippines from Periodical Literature”. Journal of East Asiatic Studies III:1 (Manila, University of Manila, 1953): pp. 109-122.

CALAVERA VAYÁ, Ana María. "Las islas Filipinas en las publicaciones de la Armada". Cuadernos Monográficos del Instituto de Historia y Cultura Naval 13 (Madrid, 1991): pp. 45-47.

CAMAGAY, María Luisa T. Social History of Manila, 1765-1898: an annotated bibliography. [Philippines]: M.L.T. Camagay, [¿1988?]. 236 pp.

CAULÍN MARTÍNEZ, Antonio. "Tratamiento de siglo XIX filipino en la bibliografía española". En: Antonio García-Abásolo (ed.), España y el Pacífico. Córdoba: Ministerio de Asuntos Exteriores, Dirección General de Relaciones Culturales-Asociación Española de Estudios del Pacífico, 1997; pp. 1-10.

CONKLIN, Harold C. Ifugao Bibliography. New Haven, Connecticut: Yale University Southeast Asia Studies, 1968. VI, 75 pp. (Bibliography Series; 11).

CRUIKSHANK, Bruce. Philippine Studies: History, Sociology, Mass Media and Bibliography, by [...] and offers. Donn V. Hart, ed. Dekalb, Ill.: Nothern Illinois University, Center for Southeast Asian Studies, 1987. 402 pp. (Occasional Papers; 6).

DÍAZ-TRECHUELO, M. ${ }^{a}$ Lourdes; Antonio F. GARCÍA-ABÁSOLO; Ana María PRIETO LUCENA; y Marta María MANCHADO LÓPEZ. "Bibliografía española de Filipinas en el siglo XX". En: Francisco de Solano y otros (eds.), Extremo Oriente ibérico. Investigaciones históricas: metodología y estado de la cuestión. Actas del I Simposium Internacional "El Extremo Oriente ibérico" (Madrid, 7-10 de noviembre de 1988). Madrid: Agencia Española de Cooperación Internacional-CSIC, Centro de Estudios Históricos, 1989; pp. 343-382.

28 Una 2. ${ }^{\text {a }}$ edición, facsimilar, a cargo de Domingo Abella, en Formosa: 1965. 55 v. Una 3. ${ }^{a}$ edición, pero en 19 v., en Mandaluyong, Rizal: Cacho Hermanos, Inc., 1973.

29 Este tomo LIII ha sido reeditado como: Bibliography of the Philippine Islands. Printed and Manuscript. Preceded by a Descriptive Account of the most important Archives and Collections containing Philippina. By James Alexander Robertson, Co-editor The Philippine Islands: 1493-1898. (Cleveland, Ohio: The Arthur H. Clark Company, 1908). New York: Kraus Reprint Co., 1970. 437 pp. 
ELIZALDE PÉREZ-GRUESO, María Dolores. "Una visión historiográfica de las coordenadas internacionales del Pacífico español, 1875-1899”. Revista de Indias 187 (Madrid, CSIC, 1989): pp. 845-862.

- Historia económica de Filipinas durante la etapa colonial española. Un estudio bibliográfico. Madrid: Fundación Empresa Pública Española, diciembre 1998. 197 pp. (Documento de Trabajo; 9813).

GARCÍA, Mauro. Philippine Numismatic Literature: A Bibliography. Manila: The Philippine Numismatic and Antiquarian Society, 1961. 56 pp.

GARCÍA-ABÁSOLO GONZÁLEZ, Antonio. "Investigaciones sobre Filipinas en Andalucía (1959-1989)". Revista de Indias 187 (Madrid, CSIC, 1989): pp. 767-778.

GARCÍA DE LOS ARCOS, María Fernanda. "Philippine Historical Studies in Mexico". Asian Research Trends: A Humanities and Social Science Review 7 (Tokyo, The Center for East Asian Cultural Studies for Unesco, 1997): pp. 1-23.

GONZÁLEZ LIQUETE, Leoncio. Repertorio histórico, biográfico y bibliográfico. (Colección de obras publicadas hasta el presente en la prensa de Manila, y ahora cuidadosamente refundidas, y otros escritos todavía inéditos). Prólogo de Jaime C. de Veyra. Manila: Imprenta del "Día Filipino", 1930. 3 v.

GONZÁLEZ POLA, Manuel (OP). Bibliografía de la provincia de Nuestra Señora del Rosario. Madrid: [Huellas Dominicanas], 1975-1980. 3 v. Es tirada aparte de Huellas Dominicanas. Contiene tres cuadernos: I (1970-1974), Madrid: 1975. 50 pp.; II (1975-1976), Madrid: 1977. 85 pp.; III (1977-1979), Madrid: 1980. 68 pp.

- "Dominicos en Extremo Oriente. Bibliografía general sobre su actividad misionera". En: Francisco de Solano y otros (eds.), Extremo Oriente ibérico, pp. 277-295.

GUERRA, Francisco. Historia de la materia médica hispano-americana y filipina en la época colonial. Inventario crítico y bibliográfico de manuscritos. Madrid: Afrodisio Aguado, 1973. 219 pp.

- "Los impresos médicos en Hispanoamérica y Filipinas durante el dominio español’. Quinto Centenario 13 (Madrid, 1987): pp. 127-146.

- Bibliografía médica americana y filipina. Período formativo/Medical Bibliography of the Americas and the Philippines. Formative Period. Madrid: Ollero y Ramos Editores, 1999. 2 v.

GUZMÁN, Abraham C. y Úrsula C. VILLARINO (comps.). Bibliography of Materials in Philippine Vernacular Languages. Manila: The National Library, Bibliography Division, 1973. XI, 914 pp.

HIDALGO NUCHERA, Patricio y Félix MURADÁS GARCÍA. La encomienda en América y Filipinas. Su impacto sobre la realidad socio-económica del mundo indígena. Bibliografía. Madrid: Imprenta Notigraf, 1999. IV, 228 pp. 
HORNEDO, Florentino H. y William Henry SCOTT. "A Bibliography of Philippine Studies". Philippine Studies XXXII:1 (Manila, The Ateneo de Manila University, 1984): pp. 53-76.

HOUSTON, Charles O. Jr. "A Preliminary Bibliography of Philippine Anthropology, Linguistics, Ethnology and Archeology". Journal of East Asiatic Studies II:2 (Manila, University of Manila, 1953): pp. 55-110.

JACQUET, Constant H. The Philippines: A Selected List of References. New York: Missionary Research Library, 1955. 10 h. Mecanografiado.

JESUS, Edilberto C. de. "An Agenda for Philippine Studies". En: Alfred McCoy y Ediberto C. de Jesus (eds.), Philippine Social History: Global Trade and Local Transformations. Manila: The Ateneo de Manila University Press, 1981; pp. 447-454.

LARKIN, John A. "The Place of Local History in Philippine Historiography". Journal of Southeast Asian History 8 (Singapore, University of Malaya in Singapore, Dpt. of History, 1967): pp. 306-317.

- (ed.). Perspectives on Philippine Historiography: A Symposium. New Haven, Conn.: Yale University Southeast Asia Studies, 1979. 74 pp. (Monograph Series; 21).

LECLERC, Charles. Bibliotheca Americana. Catalogue raisonné d'une très précieuse collection de livres anciens et modernes sur l'Amérique et les Philippines, classés par ordre alphabétique de noms d'auteurs. París: Maisonneuve et Cie, 1867. 407 pp.

- Bibliotheca Americana. Histoire, geógraphie, voyages, archéologie et linguistique des deux Amériques et des Iles Philippines. París: Maisonneuve et Cie, Libraires-Editeurs, 1878. 738 pp. Supplément n. ${ }^{\circ} 1$ (1881), 102 pp. Supplément n. ${ }^{\circ} 2$ (1887), 128 pp. Reimpresión, de la obra completa, en París: Maisonneuve et Larose, 1961.

LEROY, James A. "The Philippines, 1860-1898. Somme Comment and Bibliographical Notes". En: Emma H. Blair and James A. Robertson (eds.). The Philippine Islands, 1493-1898. Cleveland, Ohio: The Arthur H. Clark Co., 1903-1909. 55 v. Vol. LII, pp. 112-207.

LÓPEZ-RÍOS FERNÁNDEZ, Fernando. "Filipinas en el Boletín de Medicina Naval". Cuadernos Monográficos del Instituto de Historia y Cultura Naval 13 (Madrid, 1991): pp. 63-70.

LUQUE TALAVÁN, Miguel. Bibliografía española de genealogía, heráldica, nobiliaria y derecho nobiliario en Iberoamérica y Filipinas (1900-1997). Madrid: Fundación Histórica Tavera, 1999. 172 pp. (Documentos Tavera; 8).

MANILA Bibliography. A Preliminary Survey. Manila: The National Library, June 1989. V, $21 \mathrm{pp}$.

MANUEL, E. Arsenio. Philippine Folklore Biobliography; a preliminary survey. Quezon City, Philippine Islands: Philippine Folklore Society, 1955. VII, 125 pp. (Philippine Folklore Society. Paper; 1). 


\section{PATRICIO HIDALGO NUCHERA Y FÉLIX MURADÁS GARCÍA}

MARÍN Y MORALES, Valentín (OP). Ensayo de una síntesis de los trabajos realizados por las corporaciones religiosas de Filipinas, por el P. Fr. [...], profesor de la Universidad de Manila. Manila: Imprenta de Santo Tomás, 1901. 2 v. 507 pp.; 876 pp.

MARTÍNEZ CARRERAS, José Urbano y Julia MORENO GARCÍA. "Bibliografía reciente sobre la historia de Asia Oriental". En: Francisco de Solano y otros (eds.), Extremo Oriente ibérico. Investigaciones históricas: metodología y estado de la cuestión; pp. 271-275.

MARTÍNEZ VIGIL, Ramón (OP). "Bibliografía filipina. Viajes de Jagor”. Revista de Filipinas I:1 (Manila, 1875): pp. 177-182.

MATTHEWS, Mary A. Philippine independence; select list of books and articles on independence of the Philippine Islands, published since 1930. Washington, D.C.: Carnegie Endowment for International Peace Library, 1939. 7 h., mimeografiado. (Select Bibliography; 9).

MEDINA, Isagani R. Index to the 'Epistolario rizalino'(1877-1896). Quezon City: The Library, University of Philippines, 1962. IV, 44 folios. Multicop. (Research Guide; 1).

— "Filipiniana in the North American Review, 1854-1902". Journal of Philippine Librarianship I:1 (Diliman, Quezon City, University of the Philippines, Institute for Library Science, March 1968): pp. 75-83.

MEDINA, José Toribio. Bibliografía española de las Islas Filipinas (1523-1810). Santiago de Chile: Imprenta Cervantes, 1897.556 pp. Reimpreso en Amsterdam: Nico Israel, 1966.

MIRAVITE, Rosaline S. Philippine Muslims, a preliminary history and bibliography. Honolulu: 1967. $111 \mathrm{pp}$.

MOLINA, Antonio M. "Bibliografía sobre la presencia española en Filipinas impresas fuera de España”. En: Francisco de Solano y otros (eds.), Extremo Oriente ibérico; pp. 383-390.

MORAL, Bonifacio (OSA). "Catálogo de escritores agustinos españoles, portugueses y americanos y sus obras por orden alfabético de autores". Revista Agustiniana 1 (Valladolid, 1881): pp. 38-41, 127-131, 230-232, 312-315, 398-401, 465-468; 2 (1881): pp. 81-84, 371-374; 3 (1882): pp. 71-74, 377380, 452-455, 577-580, 658-661; 4 (1882): pp. 273-276, 374-377, 555-560; 5 (1883): pp. 161-166, 380-387; 6 (1883): pp. 55-60, 263-270, 474-482; 7 (1884): pp. 56-61, 251-258, 476-483; 8 (1884): pp. 448-455; 9 (1885): pp. 55-62, 253-260, 448-455; 10 (1885): pp. 230-237, 444-451; 11 (1886): pp. 60-67, 233-242, 443-450; 12 (1886): pp. 62-69, 236-243, 434-441.

- "Suplemento al Catálogo de escritores agustinos españoles, portugueses y americanos". La Ciudad de Dios 69 (El Escorial, 1906): pp. 124-127, 212229, 304-318; 70 (1906): pp. 224-229, 488-497; 72 (1907): pp. 493-495, 574-577, 654-661; 73 (1907): pp. 135-148, 216-226, 310-323, 400-409, 495- 
505; 74 (1907): pp. 56-61; 75 (1908): pp. 134-138, 487-490, 563-577; 76 (1908): pp. 508-516.

MORTON, Louis. "The Bibliography of a defeat; the search for records on the loss of the Philippines". American Archivist 16 (Chicago, Society of American Archivists, July, 1953): pp. 195-212.

MUIJZENBERG, Otto van den. Dutch Filipiniana. An Annotated Bibliography of Dutch Publications on the Philippines. Leiden: KITLV, 1992. VII, 135 pp.

NARDIN, Denis. "Bibliographie des ouvrages en français sur les Philippines". Archipel 9 (París, 1975): pp. 57-68.

— "Bibliographie des articles en français sur les Philippines". Archipel 11 (París, 1976): pp. 43-55.

ONORATO, Michael Paul (ed.). Philippine Bibliography (1899-1946). Santa Barbara, California: American Bibliography Center-CLIO, 1968. VII, 35 pp. (Bibliography and References Series; 10).

- The Philippines: A List of Doctoral Dissertations in American Universities in the Fields of Economics, History, Political Science and Sociology (19161964). New York: University of the State of New York, Foreing Area Materials Center, 1964. 4 pp.

OWEN, Norman G. "Trends and Directions of Research on Philippine History: An Informal Essay”. Asian Studies 12 (Diliman, Quezon City, University of Philippines, Institute of Asian Center, 1974): pp. 1-17.

PALAU Y DULCET, Antonio. Manual del librero hispano-americano. Bibliografía general española e hispano-americana desde la invención de la imprenta hasta nuestros tiempos, con el valor comercial de los impresos descritos. 2. ${ }^{\text {a }}$ ed., corregida y aumentada. Barcelona: 1948-1977. 28 v. Esta obra es complementada, en primer lugar, por el Indice alfabético de títulos-materias, correcciones, conexiones y adiciones del Manual del librero hispanoamericano de Antonio Palau Dulcet, por Agustín Palau Claveras. Barcelona: 1981-1987. 7 v.; y en segundo lugar, por una Addenda \& Corrigenda... al Manual del librero hispanoamericano. Barcelona: Palacete Palau y Dulcet, [1990...], v. [1]. Contenido: tomo I. A, 1-21.526.

PANIAGUA PÉREZ, Jesús. "El Extremo Oriente en los boletines de la Institución Libre de Enseñanza (1900-1936)". En: Francisco de Solano y otros (eds.), Extremo Oriente ibérico; pp. 297-309.

PARDO DE TAVERA, Trinidad Hermenegildo. Biblioteca filipina o sea, catálogo razonado de todos los impresos, tanto insulares como extranjeros, relativos a la historia, la etnografía, la lingüística, la botánica, la fauna, la flora, la geología, la hidrografía, la geografía, la legislación, etc. de las Islas Filipinas, de Joló y Marianas. Washington: Government Printing Office, 1903. 439 pp. Reeditado facsimilarmente, junto con A List of Books... de A.P.C. Griffin, con el título general de Bibliography of the Philippine Islands, en Manila: National Historical Institute, 1994. 
PASTRANA RIOL, Apolinar (OFM). "Bibliografía franciscano-filipina (18501900)". Missionalia Hispanica, año XXXIX, n. ${ }^{\circ} 116$ (Madrid, CSIC, 1982): pp. 247-365.

POLGAR, Laszlo (SJ). Bibliographie sur l'Histoire de la Compagnie de Jésus, 1901-1980. II. Les Pays. Amérique, Asie, Afrique, Océanie. Roma: Institutum Historicum Societatis Iesu, 1986. 537 pp. La bibliografía sobre Filipinas en pp. 482-490.

POSTMA, Antoon. Annotated Mangyan Bibliography (1570-1988), with Index. Panaytayan, Mansalay (Oriental Mindoro, Philippines): Mangyan Assistance and Research Center, 1988. XVII, 309 pp. (Monograph; 1).

PRIETO LUCENA, Ana María. "El Pacífico en las revistas del CSIC". Revista de Indias 187 (Madrid, CSIC, 1989): pp. 829-844.

RETANA Y GAMBOA, Wenceslao Emilio. Bibliografía de Mindanao. Epítome. Madrid: Minuesa de los Ríos, 1894. 69 pp.

- El periodismo filipino. Noticias para su historia (1811-1894). Apuntes bibliográficos, indicaciones biográficas, notas críticas, semblanzas, anécdotas. Madrid: Minuesa de los Ríos, 1895. 4 h. 646 pp. ${ }^{30}$

— "Bibliografía". En: Estadismo de las Islas Filipinas o Mis viajes por este país, por el Padre Fr. Joaquín Martínez de Zúñiga, Agustino calzado. Publica esta obra por primera vez extensamente anotada W.E. Retana. Madrid: Imprenta de la Viuda de M. Minuesa de los Ríos, diciembre 1893. 2 v. Tomo II, Apéndice B, pp. 93-352.

- Noticias histórico-bibliográficas del teatro en Filipinas desde su origen hasta 1898. Madrid: Suárez, 1910. 181 pp.

— "Bibliografía Rizalina (Epítome). Lista de los trabajos literarios y científicos escritos por Rizal desde el año de 1875 hasta la víspera de su muerte”. En: Vida y escritos del Dr. José Rizal, por W. E. Retana. Edición ilustrada con fotograbados. Prólogo y epílogo de Javier Gómez de la Serna y Miguel de Unamuno respectivamente. Madrid: Librería General de Victoriano Suárez, 1907. XVI, 512 pp.; láms.; pp. 457-474.

- Noticia de las principales publicaciones sobre Filipinas. Madrid: 1920.7 pp.

RICHARDSON, Jim (comp.). Philippines. Oxford: Clio Press, 1989. XXX, 373 pp.: map. (World Bibliographical Series; 106).

ROBERTSON, James Alexander. Bibliography of the Philippine Islands. Printed and Manuscript. Preceded by a Descriptive Account of the most important Archives and Collections containing Philippina. By [...], Co-editor The

30 Considerablemente aumentada, constituye la monografía que va al final del Aparato bibliográfico de la Historia General de Filipinas deducido de la colección que posee en Barcelona la Compañía General de Tabacos de dichas islas. Madrid: Minuesa de los Ríos, 1906. 3 v. Reimpreso en Manila: Pedro B. Ayuda, 1964. (Philippine Historical Series; 1). 
Philippine Islands: 1493-1898. (Cleveland, Ohio: The Arthur H. Clark Company, 1908). New York: Kraus Reprint Co., 1970. 437 pp. ${ }^{31}$

- "Bibliography of early Spanish-Japanese Relations, compiled from manuscripts and books in the Philippine Library". Transactions of the Asiatic Society of Japan 43:1 (Tokyo, The Asiatic Society of Japan, 1915): pp. 1-170. Reimpreso en Tokyo: Yushodo Booksellers, 1964. 170 pp.

RODRÍGUEZ RODRÍGUEZ, Isacio (OSA). Bibliografía misional agustiniana. Valladolid: Imprenta Agustiniana, 1958. 217 pp. Reimpreso del Archivo Histórico Hispano-Agustiniano 49 (Madrid, 1955): pp. 209-257; 50 (1956): pp. 117-144; 261-278; 51 (1957): pp. 97-134; 259-288; 52 (1958): pp. 95110.

RODRÍGUEZ RODRÍGUEZ, Isacio (OSA) y Jesús ALVAREZ (OSA). Labor científico-literaria de los agustinos españoles. Valladolid: Estudio Agustiniano, 1992. 2 v. Vol I (1913-1964); 575 pp. Vol. II (1965-1990); 577 pp. En curso de publicación.

SAITO, Shiro. Philippine Etnography. A Critically Annotated and Selected Bibliography. 2. ${ }^{a}$ ed. Honolulu, Hawaii: The University Press of Hawaii, 1974. XXXI, 512 pp. Una 1. a ed. en 1972.

SÁNCHEZ ALONSO, Benito. Fuentes de la Historia española e hispanoamericana. Ensayo de Bibliografía sistemática de impresos y manuscritos que ilustran la Historia política de España y sus antiguas provincias de

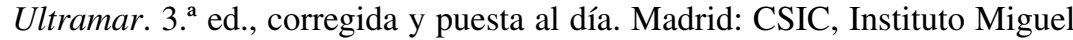
de Cervantes, Publicaciones de la Revista de Filología Española, 1952. 3 v. 678,508 y 736 pp. $^{32}$

SÁNCHEZ GÓMEZ, Luis Angel. "Recent Philippine Historical Studies in Spain". Asian Research Trends: A Humanities and Social Science Review 5 (Tokyo, The Center for East Asian Cultural Studies for Unesco, 1995): pp. 1-23.

31 Se trata de una reedición del volumen LIII (Bibliography) de la obra: The Philippine Islands, 1493-1898: Explorations by early navigators, descriptions of the Islands and their people and records of the catholic missions, as related in contemporaneous books and manuscripts, showing the political, economic, commercial and religious conditions of those Islands from their earliest relations with european nations to the close of the nineteenth century. Translated from the originals. Edited and anotated by Emma Helen Blair and James Alexander Robertson, with historical introduction and additional notes by Edward Gaylord Bourne. With maps, portraits and other illustrations. Cleveland, Ohio: The Arthur H. Clark Co., 1903-1909. 55 v.

32 La primera edición, que excluía América, es de 1919 y tenía el siguiente título: Fuentes de la Historia española. Ensayo de bibliografía sistemática de las monografías impresas que ilustran la Historia política nacional de España, excluidas sus relaciones con América. Prólogo de Rafael Altamira. Madrid: Junta para Ampliación de Estudios, 1919. XXI, 448 pp. En 1927 se publicó una segunda edición aumentada y corregida con el título de Fuentes de la Historia española e hispanoamericana. Ensayo de bibliografía sistemática de impresos y manuscritos que ilustran la Historia política de España y sus antiguas provincias de Ultramar. Segunda edición, ampliada y revisada. Madrid: Centro de Estudios Históricos, 1927. 2 v. 633 pp., 468 pp. En 1946 se publicó un apéndice en Madrid: Consejo Superior de Investigaciones Científicas, 1946. 464 pp. 
SANTIAGO VELA, Gregorio de (OSA) ${ }^{33}$ Ensayo de una biblioteca ibero-americana de la Orden de San Agustín. Por el Padre [...], de la Provincia del Smo. Nombre de Jesús. Obra basada en el Catálogo bio-bibliográfico agustiniano del P. Bonifacio Moral, Ex Provincial de la Matritense. Publícase a expensas de la expresada Provincia de Filipinas. Madrid: Imprenta del Asilo de Huérfanos del S.C. de Jesús, 1913-1931. 8 v. (Falta el 4. ${ }^{\circ}$, letras J-LL, no publicado).

SCHUMACHER, John N. (SJ) y Gerald H. ANDERSON. "A Bibliographical Survey of Philippine Church History". En: Gerald H. Anderson (ed.), Studies in Philippine Church History. Ithaca and London: Cornell University Press, 1969; pp. 389-412.

SEE, Chinben. A Bibliography of the Chinesse in the Philippines. Cagayán de Oro City, Philippines: Xavier University, 1970. 97 pp.

- y Teresita Ang SEE. Chinesse in the Philippines: a Bibliography. Manila: De la Salle University, China Studies Program, 1990. XIV, 208 pp.

SIMÓN DÍAZ, José. Bibliografía de la literatura hispánica. Prólogo de Joaquín de Entrambasaguas. 3. ${ }^{\text {a }}$ ed. corregida y actualizada. Madrid: CSIC, Instituto Miguel de Cervantes de Filología Hispánica, 1983... 16 v. En curso de publicación.

STREIT, Robert (OMI) y Johannes DINDINGER (OMI). Missionsliteratur indiens der Philippinen, Japans und Indochinas, 1700-1799. Verlag: Franziskus Xaverius Missionsverein, Zentrale in Aachen, 1931. 616 pp. (Bibliotheca Missionum; 6).

- Missionsliteratur der Philippinen, 1800-1909. Verlag: Franziskus Xaverius Missionsverein, Zentrale in Aachen, 1937. 996 pp. (Bibliotheca Missionum; 9).

TIAMSON, Alfredo T. Mindanao-Sulu Bibliography. Containing Published, Unpublished Manuscripts and Works-in-Progress. A Preliminary Survey and W.E. Retana's Bibliografía de Mindanao (1894). 2. ${ }^{a}$ ed. Davao City, Philippines: Ateneo de Davao, 1979. XVII, 344 pp. Una 1. a edición en 1970.

- The Muslim Filipinos: an annotated bibliography. Manila: Office of the Special Assistant on Cultural Communities Department of Public Information, Malacañang, 1977. XXX, 282 pp. [22] pp.

TOGORES SÁNCHEZ, Luis Eugenio. "Fuentes documentales y bibliográficas españolas para el estudio de la revuelta tagala de 1896/97 en Filipinas". Revista Española del Pacífico 6 (Madrid, 1996): pp. 71-81.

33 Sobre este autor, vid. Abella, Pedro (OSA), "Biografía del R.P. Gregorio de Santiago [Vela]". Archivo Histórico Hispano-Agustiniano 22 (Madrid, 1924): pp. 12-18. Ibeas, Bruno (OSA), "Un bibliógrafo ilustre [P. Gregorio de Santiago Vela, OSA]". Archivo Histórico Hispano-Agustiniano 22 (Madrid, 1924): pp. 117-118. Pinta Llorente, Miguel de la (OSA). "Aportaciones bio-bibliográficas inéditas para el Ensayo del P. Gregorio Vela". Archivo Histórico Hispano-Agustiniano 49 (Madrid, 1955): pp. 361-375 
TORMO SANZ, Leandro. "Bibliografía sobre historia de la Iglesia en el Extremo Oriente relacionado con España”. En: Francisco de Solano y otros (eds.), Extremo Oriente ibérico; pp. 391-413.

UNIVERSITY OF CHICAGO. PHILIPPINE STUDIES PROGRAM. Selected bibliography of the Philippines. Topically arranged and annotated, prepared by Philippine Studies Program, The University of Chicago, Fred Eggan, director, E.D. Hester, associate director. Prelim. ed. Westport, Conn.: Greenwood Press, 1973. VI, 138 pp. Una 1. ${ }^{a}$ ed. en New Haven, Conn.: Human Relations Area Files, 1956. 138 pp. (Behavior Science Bibliography).

VELASCO, Mariano (OP). Ensayo de bibliografía de la Provincia del Santísimo Rosario de Filipinas. Manila: Universitas Sancti Thomas, 1960. 6 v. Mecanografiado. ${ }^{34}$

YABES, Leopoldo Y. y José Resurrección CALIP (comps.). "An Iloiko bibliography of works pertaining to the Iloiko people and their language". En: Leopoldo Y. Yabes, A brief survey of Iloiko literature from the beginnings to its present development, with a bibliography of works pertaining to the Iloiko people and their language. Manila: The Autor, 1936; pp. 75-155.

ZAMORA, Mario D. y José Y. ARCELLANA (eds.). A Bibliography of Philippine Anthropology. Baguio City: University of the Philippines at Baguio Publication, 1970. 164 pp. $^{35}$

\section{Tipobibliografías}

ARTIGAS Y CUERVA, Manuel. La primera imprenta en Filipinas. Reseña histórica bio-bibliográfica, con tres apéndices. Uno bibliográfico de las obras citadas en el texto; otro con la biografía del P. Blancas y, el último, con una reseña de los actos llevados a cabo para celebrar por primera vez el Centenario de la Imprenta en Filipinas. Colócase además un trabajo sobre Pinpin, con el famoso libro de este filipino. Manila: Tipo-Litografía Germania, 1910. XII, 259, XVII pp. (Biblioteca Nacional Filipina; 6).

LOON, Piet van der. "The Manila Incunabula and Early Hokkien Studies". Asia Major. A British Journal of Far Eastern Studies, New Series, XII:1 (London, 1966): pp. 1-43.

MEDINA, José Toribio. La imprenta en Manila, desde sus orígenes hasta 1810. Santiago de Chile: 1896. 280 pp. Reeditado facsimilarmente en Valencia: Librerías París-Valencia, 1993. 280 pp.

34 Un ejemplar se halla en la biblioteca del convento de San Pedro Mártir que los PP. dominicos de la provincia del Santo Rosario poseen en Alcobendas (Madrid).

35 Se trata de un número especial de Verge, publicación académica de la Universidad de Filipinas en Baguio. 
- Brevísimo epítome de la 'Imprenta en Manila (1593-1810)' para servir de índice a la obra sobre la misma materia que tiene para dar a la prensa José Toribio Medina. Madrid: Viuda de M. Minuesa de los Ríos, 1896. 32 pp.

- La imprenta en Manila, desde sus orígenes hasta 1810. Adiciones y ampliaciones. Santiago de Chile: Impreso y grabado en casa del autor, 1904. 203 pp. Reeditado facsimilarmente en Valencia: Librerías París-Valencia, 1992. 203 pp.

PARAMOS, José González. "Apuntes sobre la primera imprenta y el primer periódico de Iloilo". Cultura Filipina I:3 (1910): pp. 224-233.

- Apuntes para la historia de la imprenta en Iloilo (1875-1911). Iloilo: Tipografía "La Editorial", 1911. 30 pp.

PARDO DE TAVERA, Trinidad Hermenegildo. Noticias sobre la imprenta y el grabado en Filipinas. Madrid: Tipografía de los Hijos de M.G. Hernández, 1893. $48 \mathrm{pp}$.

PÉREZ, Angel (OSA) y Cecilio GÜEMES (OSA). Adiciones y continuación de 'La imprenta en Manila' de J.T. Medina, o rarezas y curiosidades bibliográficas filipinas de las bibliotecas de esta capital. Manila: Imprenta de Santos y Bernal, 1905. 620 pp.

PRINTED in the Philippines, 1593-1993: a commemorative exhibition on the fourth centennial of printing in the Philippines. Pamphlet. Manila: The University of Santo Tomas Central Library in cooperation with the Embassy of Spain in the Philippines, 1993.

QUIRINO, Carlos. "The First Philippine Imprints". The Journal of History VIII (Manila, Philippine National Historical Society, 1960): pp. 219-228.

RETANA Y GAMBOA, Wenceslao Emilio. Brevísimo epítome de la Imprenta en Manila (1593-1810), para servir de índice a la obra de José Toribio Medina. Madrid: Minuesa de los Ríos, 1896. 32 pp.

- La imprenta en Filipinas (1593-1810). Con una demostración gráfica de la originalidad de la primitiva. Adiciones y observaciones a 'La imprenta en Manila'de D. J[osé] T[oribio] Medina. Madrid: Viuda de M. Minuesa de los Ríos, 1899. 275 pp. (En la portada la fecha es: 1897).

— "La censura de imprenta en Filipinas". Nuestro Tiempo, año VII, n. 107 (Madrid, noviembre 1907): pp. 192-231. Hay tirada aparte en Madrid: Victoriano Suárez, 1908. 40 pp.

- Tablas cronológica y alfabética de imprentas e impresores de Filipinas (1593-1898). Madrid: Imprenta Fortanet, 1908. 114 pp.

- Orígenes de la imprenta filipina: investigaciones históricas, bibliográficas y tipográficas. Obra premiada en certamen internacional celebrado en Manila, en 1910. Madrid: Librería General de Victoriano Suárez, 1911. 204 pp. ${ }^{36}$

36 Esta obra incluye, del propio Retana, una "Bibliografía de los incunables filipinos (15931640)", en pp. 65-184. 
SÁNCHEZ FUERTES, Cayetano (OFM). "Los franciscanos y la imprenta en Filipinas. (Notas para la historia de la imprenta franciscana, 1578-1846)". Missionalia Hispanica, año XXXVIII, n. ${ }^{\circ} 112$ (Madrid, CSIC, 1981): pp. 5-58 y año XXXIX, n. ${ }^{\circ} 116$ (1982): pp. 367-412.

— "Crónica de unas 'Chrónicas'. Aportación al estudio de la imprenta franciscana en Filipinas”. Archivo Ibero-Americano, tomo XLIX, n. ${ }^{\circ}$ 195-196 (Madrid, 1989): pp. 491-530.

— "La imprenta franciscana en Filipinas en el siglo XVII". En: Actas del III Congreso Internacional sobre los franciscanos en el Nuevo Mundo (siglo XVII). La Rábida: 18-23 de septiembre de 1989. Madrid: Deimos, 1991; pp. $1053-1098 .{ }^{37}$

TROTA JOSÉ, Regalado. Impreso. Philippine Imprints, 1593-1811. Makati, Metro-Manila, Philippines: Fundación Santiago and Ayala Foundation Inc., 1993. 312 pp.

\section{Catálogos impresos de fondos bibliográficos filipinos en instituciones culturales (bibliotecas, archivos, universidades)}

\section{España}

\section{Córdoba}

— Biblioteca Municipal

ÁLVAREZ MAESTRE, María del Valle. "Fondos para el estudio de Filipinas en la Biblioteca Municipal de Córdoba”. En: El Lejano Oriente español: Filipinas (siglo XIX). VII Jornadas Nacionales de Historia Militar. Sevilla, 5-9 de mayo de 1997. Sevilla: Capitanía General de la Región Militar Sur, Cátedra “General Castaños”, 1997; pp. 169-182.

León

— Biblioteca de Don Gumersindo de Azcárate

PANIAGUA PÉREZ, Jesús. "Fondos relativos al Extremo Oriente en la biblioteca de Don Gumersindo de Azcárate en León”. En: Francisco de Solano y otros (eds.), Extremo Oriente ibérico; pp. 311-322.

37 Las Actas... se publicaron igualmente como número extraordinario de la revista Archivo Ibero-Americano, segunda época, año L, tomo L, n. ${ }^{\circ}$ 197-200. (Madrid, 1990). 


\section{PATRICIO HIDALGO NUCHERA Y FÉLIX MURADÁS GARCÍA}

Madrid

— Biblioteca Nacional de España

CUESTA, María Luisa. Catálogo de obras iberoamericanas y filipinas de la Biblioteca Nacional de Madrid. Prólogo del Ilmo. Sr. D. Francisco Sintes Obrador. Madrid: Ministerio de Educación Nacional, Dirección General de Archivos y Bibliotecas, 1953. 322 pp.

\section{Valladolid}

— Colegio de los Agustinos Filipinos

BLANCO, Antonio (OSA). Biblioteca bibliográfico-agustiniana [del Colegio de Filipinos] de Valladolid, ordenada por el R.P. [...], agustino, profesor de número del grado de regente, maestro de profesos y bibliotecario en el Real Colegio de Filipinos. Valladolid: Tipografía de José Manuel de la Cuesta, 1909. 629 pp.

RODRÍGUEZ RODRÍGUEZ, Isacio (OSA)..$^{38}$ Updated Checklist of Filipinana at Valladolid. Manila: National Historical Institute, 1976. 2 v. 836 pp.

TUBANGUI, Helen R. (ed.). A Catalog of Filipiniana at Valladolid. Manila: The National Library of the Philippines; The Ateneo de Manila University Press, 1973. XV, 364 pp. (The Bibliographical Series; 4).

Bibliotecas hoy dispersadas

— Biblioteca del Museo-Biblioteca de Ultramar ${ }^{39}$

[VIGIL, Francisco de P.]. Catálogo del Museo-Biblioteca de Ultramar. Madrid: Imprenta sucesora de M. Minuesa de los Ríos, 1900. 350 pp.

— Biblioteca de D. Antonio Graíño ${ }^{40}$

SANZ LÓPEZ, Carlos. Bibliografía descriptiva y crítica de libros filipinos de Don Antonio Graíño. Manila: Instituto Nacional de Historia, 1976. 300 pp.

38 Está preparando una nueva edición, muy aumentada, de la Filipiniana del convento de los Agustinos Filipinos de Valladolid.

39 Al cerrarse, la mayor parte de sus fondos pasaron a la Biblioteca Nacional, aunque un lote de 856 libros fueron al Museo de América.

40 Adquirida en 1957 por el Estado español, el cual la distribuyó entre la biblioteca del Instituto de Cultura Hispánica, hoy Biblioteca Hispánica de la AECI, y la Biblioteca Nacional de España. 
— Biblioteca de D. Wenceslao E. Retana ${ }^{41}$

RETANA Y GAMBOA, Wenceslao Emilio. Catálogo de la biblioteca filipina de W.E. Retana. Edición de treinta ejemplares. Madrid: Imprenta de la Viuda de M. Minuesa de los Ríos, 1893. 122 pp.

— "Epítome de la Bibliografía General de Filipinas, por [...]. Parte Primera. Obras que posee el autor". En: Wenceslao E. Retana, Archivo del Bibliófilo Filipino: recopilación de documentos históricos, científicos, literarios y políticos y estudios biográficos por [...]. Madrid: M. Minuesa de los Ríos, 18951905. 5 v. Tomo I (1895), sin paginación; 84 pp. Tomo II (1896), pp. 455510; 56 pp. Tomo III (1897), pp. 499-546; 48 pp. Tomo IV (1898), pp. 447-544; 98 pp.

- Catálogo abreviado de la biblioteca filipina de W.E. Retana. Madrid: Minuesa de los Ríos, 1898. XXXVIII, 652 pp. ${ }^{42}$

- Catálogo de las obras filipinas que ofrece en venta W.E. Retana. Barcelona: 1902.

— Biblioteca de la Compañía General de Tabacos de Filipinas ${ }^{43}$

RETANA Y GAMBOA, Wenceslao Emilio. Aparato bibliográfico de la Historia General de Filipinas deducido de la colección que posee en Barcelona la Compañía General de Tabacos de dichas islas. Madrid: Minuesa de los Ríos, 1906. 3 v. Reimpreso en Manila: Pedro B. Ayuda, 1964. (Philippine Historical Series; 1).

\section{— Librería de Don Pedro Vindel}

VINDEL ALVAREZ, Pedro. Catálogo sistemático e ilustrado de la Biblioteca Filipina reunida y puesta en venta por P. Vindel. * Grandes publicaciones. Jurisprudencia y legislación. Agricultura. Industria. Comercio. Ciencias. Arte y letras. Materias varias. Política. Madrid: calle del Prado, núm. 9, 1904. 444 pp. (Número 15. Julio-Agosto, 1904).

- Catálogo de la Biblioteca Filipina reunida y puesta en venta por P. Vindel. ** Historia. Madrid: calle del Prado, núm. 9, 1905. 378 pp. (Número 16. 1905). Barcelona.

41 En 1900, Retana la vendió a la Compañía General de Tabacos de Filipinas, radicada en

42 Parte de este catálogo se había publicado en la obra "Epítome..." anteriormente citada.

43 Más que de dispersada, hay que hablar en este caso de destruida. Iniciada en 1883, en 1900 aumentó considerablemente debido a la adquisición de la biblioteca particular de Retana; en 1904 compró gran número de libros al librero Pedro Vindel. En 1912 fue vendida al gobierno de Filipinas por 200.000 pesos. Instalada en el Palacio de la Asamblea Nacional, fue casi totalmente destruida en 1945 en la batalla de Manila. 
- Biblioteca Oriental. Comprende 2.747 obras relativas a Filipinas, Japón, China y otras partes de Asia y Oceanía. Con comentarios y 96 reproducciones en facsímil, 15 de ellas tiradas aparte en excelente papel de hilo. Madrid: P. Vindel, Librero-Anticuario, 1911-1912. 2 v. 436 pp.; 251 pp. (Catálogo de la librería de P. Vindel; 4 y 5).

- Biblioteca Ultramarina. Obras referentes a América, Filipinas, Japón, China y otros países que se ofrecen en venta por P. Vindel... Madrid: Mendizábal núm. 73, 1916. 324 pp.

\section{Estados Unidos de América del Norte}

Dekalb, Illinois

— Nothern Illinois University

DUTTON, Lee S. (comp.). A Checklist of Philippine Pamphlet Holdings of Nothern Illinois University Libraries. DeKalb, Ill.: Nothern Illinois University, Center for Southeast Asian Studies, 1975. II, 57 pp. (Bibliographical Publication; 4).

Chicago, Illinois

— The Newberry Library, University of Chicago

BUTLER, Ruth Lapham. "The Filipiniana of the Ayer Collections: The Rizaliana". Journal of History 10 (Manila, Philippine National Historical Society, 1962): pp. $42-55$.

PHELAN, John Leddy. "The Philippine Collection in the Newberry Library". The Newberry Library Bulletin III (Chicago, marzo 1955): pp. 229-236.

WELSH, Doris Varner (comp.). Checklist of Philippine Linguistics in the Newberry Library. Chicago, Illinois: The Newberry Library, 1950. VI, 176 pp.

- (comp.). A Catalogue of Printed Materials relating to the Philippine Islands 1519-1900 in the Newberry Library. Chicago, Illinois: The Newberry Library, 1959. VIII, 179 pp.

New York City, New York

— The New York Public Library

"Works relating to the Philippine Islands in the New York Public Library". Bulletin of the New York Public Library IV:1 (New York, January 1900): pp. 19-29. 
Philadelphia, Pennsylvania

— The Free Library

MIDDLETON, Thomas Cooke (OSA). "Some Notes on the Bibliography of the Philippines". Bulletin of the Free Library of Philadelphia 4 (December 1900). Hay edición aparte en Philadelfia: The Free Library of Philadelphia, 1900. 37 pp.

\section{Washington, District of Columbia}

\section{— The Library of Congress}

GRIFFIN, Appleton Prentiss Clark. A List of Books (with references to Periodicals) on the Philippine Islands in the Library of Congress. By [...], Chief of Division of Bibliography. With Chronological List of Maps in the Library of Congress, by P. Lee Phillips, Chief of Division Maps and Charts. Washington, D.C.: Government Printing Office, 1903. XV, 397 pp. Reeditado facsimilarmente, junto con la Biblioteca Filipina... de Trinidad H. Pardo de Tavera, con el título general de Bibliography of the Philippine Islands, en Manila: National Historical Institute, 1994.

- Library of Congress. List of works relating to American Occupation of the Philippine Islands 1898-1903. Washington D.C.: Government Printing Office, 1905. 100 pp.

RONY, A. Kohar (comp.). Philippine Holdings in the Library of Congress, 19601987: a Bibliography. Washington, D.C.: Library of Congress, 1993. XI, $702 \mathrm{pp}$.

\section{Filipinas}

\section{General}

FERRER, Maxima Magsanoc. Union Catalog of Philippine Materials. Compiled and Edited by [...], Library Coordinator Inter-Departmental Reference Service, College of Public Administration, University of the Philippines. With an Introduction by Carlos P. Rómulo. Quezon City: University of Philippine Press, 1970-1976. 1738 pp. 2 v. Vol. I (A to O); vol. II (P to Z). ${ }^{44}$

44 Se trata de un catálogo de los libros que existen en 201 bibliotecas de Filipinas. El volumen II lo coedita la citada University of Philippine Press con la National Library. 
PATRICIO HIDALGO NUCHERA Y FÉLIX MURADÁS GARCÍA

Dumaguete City

— Silliman University

A CLASSIFIED annotated bibliography of selected Filipiniana materials at the Silliman University Library. Dumaguete City: Silliman University, 1977. $358 \mathrm{pp}$.

Manila

- Ayala Compañía

AYALA COMPAÑÍA LIBRARY. Relación de libros contenidos en la biblioteca de la Compañía Ayala en diciembre de 1960. Makati, MetroManila: Ayala Compañía, 1961.

— De La Salle College Library

BERMÚDEZ, Roberto A. (comp.). Filipiniana Holdings of De La Salle College Library. Introduction and annotations by Marcelino A. Foronda, Jr. Manila: De La Salle College Libraries, 1970. III, 236 pp. (Bibliography Series; 1).

- Filipiniana Holdings of De La Salle College Library, January 1970 to May 1973. Manila: De La Salle College Libraries, 1974. 96 pp. (Bibliography Series; 1, Supplement).

— Eastern University

EASTERN UNIVERSITY LIBRARY. Classified List of Filipiniana Books and Pamphlets in the Filipiniana Research Section. Far Eastern University Press.

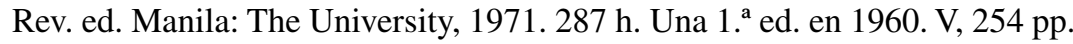

— The López Memorial Museum

GARCÍA, Mauro. Philippine Rariora. A Descriptive Catalog of 17th Century Imprints in the López Memorial Museum, by [...], with a Forewood by Oscar M. López. Metro Manila, Philippines: Eugenio López Foundation, Inc., 1983. XXIII, 103 pp., ill.

LÓPEZ MEMORIAL MUSEUM. PASAY CITY. Classified list (partial) of Filipiniana books, pamphlets and periodicals in the library López Memorial Museum. Pasay City: The Museum, 1960. 98 pp. 
GUÍA BIBLIOGRÁFICA PARA LA HISTORIA DE FILIPINAS, 1565-1898

LÓPEZ MEMORIAL MUSEUM. PASAY CITY. Early Philippine Imprints in the López Memorial Museum. Manila: The Museum, 1961. VIII, 45 pp.

LÓPEZ MEMORIAL MUSEUM. PASAY CITY. Catalogue of Filipiniana Materials in the López. Memorial Museum. Pasay City: The Museum, 19621971. 5 v. v. I, 1962. VIII, 162 pp.; v. II, 1965. VII, 181 pp.; v. III, 1967. VII, 140 pp.; v. IV, 1969. VII, 161 pp.; v. V, 1971. IX, 195 pp.

— Marcelino A. and Cresencia R. Foronda Private Collection

FORONDA, Marcelino A. Jr. An Iloiko Bibliography: a Listing of Iloiko Materials in the Foronda Private Collection. Manila: De La Salle College Library, 1972. XIV, 253 pp. (Bibliographical Series; 2).

FORONDA, Marcelino A. y Cresencia R. FORONDA. A Filipiniana Bibliography, 1743-1982. (A Classified Listing of Philippine Materials in the Marcelino A. and Cresencia $R$. Foronda Private Collection). Manila: Philippine National Historical Society, 1981. XVI, 307 pp.

- Museo-Biblioteca de Filipinas ${ }^{45}$

PERDIGUERO, Benito (comp.). Museo-Biblioteca de Filipinas. Catálogo de las obras existentes en la Biblioteca. Manila: Chofré y Cía, 1897. 137 pp.

— The National Library

BAYLON, Concepción S. The National Library. Guide to Doctoral Dissertations on Microfilm (1937-1968) in the Filipiniana Division. Prepared by [...]. Manila: The National Library, Filipiniana Division, 1971. (TNL Research Guide Series; 3).

MEDINA, Isagani R. (Compiled and Edited by). Filipiniana Materials in the National Library. Quezon City: The National Library; The University of the Philippines Press, 1971. XVIII, 353 pp.

45 Institución creada por Real Orden del Gobierno español de 12 agosto 1887. Llegó a tener unos 1.500 libros. Uno de sus directores fue Pedro Alejandro Paterno. La institución fue disuelta tras la llegada de los norteamericanos a Manila y los fondos fueron llevados por Paterno a su residencia. El destino posterior de la biblioteca no está claro; parece que sus fondos se unieron a la American Circulating Library. Vid. al respecto, Vicente S. Hernández, History of books and libraries in the Philippines, 1521-1900: a study of the sources and chronology of events pertaining to Philippine library history from the sixteenth to the end of the nineteenth century. Manila: The National Comission for Culture and Arts, 1996. XVI, 248 pp.; especialmente, pp. 68-74. El Museo-Biblioteca se considera el antecedente de la actual The National Library. 
ORBASE, Lily O. y Leticia C. CALANGI (comps.). A Guide to the Balmaceda Collection. Manila: The National Library of the Philippines, 1980. VII, 366 pp. (The Research Guide Series; 13). ${ }^{46}$

ROSA, Benita S. de la. "Filipiniana in the National Library". The Philippine Colophon III:3-4 (Manila, The Philippine Booklovers Society, JulyDecember 1965): pp. 15-22.

— Universidad de Santo Tomás

GAYO ARAGÓN, Jesús (OP). “Catálogo de impresos filipinos conservados en los archivos de la Provincia del Santísimo Rosario de Filipinas y de la Universidad de Santo Tomás de Manila". Unitas XXV:2 (Manila, Universidad Pontificia de Santo Tomás, Abril 1952): pp. 313-368; XXV:3 (Julio 1952): pp. 584-615; XXV:4 (Octubre 1952): pp. 830-856; XXVIII:1 (Enero-Marzo 1955): pp. 115-153.

Sagada, Mountain Province

— Igorot Study Center

HAKCHOLNA, William (comp.). "Catalogue of works on Cordillera etnography in the Igorot Study Center, Sagada, Mountain Province”. Saint Louis Quarterly VII:1 (Baguio, Philippines, Saint Louis University, March 1964): pp. 113-142.

- Catalogue of published works on Cordillera etnography in the Igorot Study Center, Sagada, Mountain Province; new accesions 1969. Sagada: s.i., 1970. 11 pp. mimeo. (Supplement; 2).

\section{Japón}

Tokyo

— The Toyo Bunko (The Oriental Library)

SEMINAR ON SOUTH AND SOUTH-EAST ASIAN HISTORY. Classified Catalogue of Books in Western Languages on South-East Asia in the Toyo Bunko. Edited by the Seminar on South and South-East Asian History. Tokyo: The Toyo Bunko (The Oriental Library), 1978. V, 317 pp. Los libros de Filipinas en pp. 229-256.

46 Esta obra describe la colección Balmaceda, depositada en la Filipiniana Division de la Biblioteca Nacional de Filipinas. La citada colección fue adquirida por dicha biblioteca a los herederos de Julián Cruz Balmaceda, de Bacoor, Cavite, eminente poeta tagalo. El catálogo contiene 2.004 entradas de una amplia serie de fuentes de temas filipinos, especialmente literatura vernácula. 


\section{Repertorios biográficos ${ }^{47}$}

\subsection{Generales}

AGATON, Leo F. The character of our heroes. Manila: M. Colcol, 1962. 122 pp. ill. ARCHIVO biográfico de España, Portugal e Iberoamérica. [Microforma]. Una compilación de 300 obras biográficas entre el siglo XVII y los inicios del siglo XX. Dirección y redacción, Víctor Herrero Mediavilla y Rosa Aguayo Nayle. München: Saür, [1986-1989]. XXXIX, 1105 microfichas; negativo; 11 x $15 \mathrm{~cm}+1$ v. (64 pp.).

ARCHIVO biográfico de España, Portugal e Iberoamérica (Nueva serie). [Microforma]: ABEPI II. Dirección y redacción, Víctor Herrero Mediavilla. München: Saür, [1991-1993]. XLII, 976 microfichas; negativo; 11 x $15 \mathrm{~cm}$.

ARCHIVO biográfico de España, Portugal e Iberoamérica, 1960-1995. [Microforma]. Editor, Víctor Herrero Mediavilla. Edición, Diazo Edition. München: Saür, 1996. 447 microfichas; negativo; 11 x $15 \mathrm{~cm} .{ }^{48}$

CASTELLANOS DE LOSADA, Basilio Sebastián (dir.). Biografía eclesiástica completa. Vida de los personajes del Antiguo y Nuevo Testamento, de todos los santos que venera la Iglesia, Papas y eclesiásticos célebres por sus virtudes y talentos en orden alfabético. Redactada por una comisión de eclesiásticos y literatos, revisada por una comisión nombrada por la autoridad eclesiástica, bajo la dirección del P. [...]. Madrid: Imprenta de Aguado; Barcelona: Imprenta de J.M.Grau, 1848-1868. $30 \mathrm{v}$.

GALANG, Zoilo M. (ed.). Encyclopedia of the Philippines. Manila: Exequiel Floro, 1950-1958. 20 v. Vols. 3-4, Biography.

GARCIA, Mauro (comp.). Philippine Pseudonymus, Aliases, Pen Names, Pet Names, Screen Names and Name Aberrations. Compiled by [...] and augmented with a introduction and bibliographical sources and annotated by Gabriel A. Bernardo and Isagani R. Medina. Manila: UNESCO National Commission of the Philippines, 1965. XX, $157 \mathrm{pp}$.

MANUEL, E. Arsenio. Dictionary of Philippine Biography. Quezon City: Filipiniana Book Guild, [1955-1995]. 4 v. (Filipiniana Publications Biography Series). Los vols. 3 y 4 en coedición con Magdalena Avenir MANUEL. v. I, 1955. XIII, 512 pp. v. II, 1970. XI, 502 pp. v. III, 1986. XV, 566 pp. v. IV, 1995. XI, 606 pp.

47 Vid. además el citado de Gendrano, Victor P., en el epígrafe 1.1.

48 Los tres ABEPI citados se acompañan del Indice biográfico de España, Portugal $e$ Iberoamérica. 3. ${ }^{\mathrm{a}}$ edición, corregida y ampliada, editada y dirigida por Víctor Herrero Mediavilla, en München: K.G. Saür, 2000. 10 v. (XXXIII, 3586 pp.). La 1. ${ }^{a}$ edición, editada y dirigida por Víctor Herrero Mediavilla y Rosa Aguayo Nayle, en München: Saür, 1990. 4 v. (1429 pp.). Una 2. a edición, corregida y ampliada, editada y dirigida por Víctor Herrero Mediavilla, en München: K.G. Saür, 1995. 7 v. (XLIV, 3315 pp.). Se dispone también de los índices actualizados en CD-ROM. 
RETANA Y GAMBOA, Wenceslao Emilio. Tablas cronológica y alfabética de imprentas e impresores de Filipinas (1593-1898). Madrid: Imprenta Fortanet, 1908. 114 pp.

- "Indice biográfico de los que asistieron al descubrimiento de las Islas Filipinas". Raza Española 27 (Madrid, 1921): pp. 9-88.

- Indice de personas nobles y otras de calidad que han estado en Filipinas desde 1521 hasta 1898. Madrid: Librería de Victoriano Suárez, 1921. 84 pp.

- Breve diccionario biográfico de los ingenieros militares que han estado en las Islas Filipinas desde 1565 hasta 1898. Madrid: 1923. 91 pp.

ZAIDE, Gregorio F. Great Filipinos in History. An Epic of Filipino Greatness in War and Peace. Manila, Philippines: Verde Book Store, 1970. X, 675 pp., ill.

\subsection{Repertorios biográficos de religiosos en Filipinas}

\subsubsection{Clero secular}

GUITARTE IZQUIERDO, Vidal. Episcopologio español (1700-1867). Españoles obispos en España, América, Filipinas y otros países. Roma: Instituto Español de Historia Eclesiástica, 1992. 260 pp. (Subsidia; 29).

- Episcopologio español (1500-1699). Españoles obispos en España, América, Filipinas y otros países. Roma: Instituto Español de Historia Eclesiástica, 1994. 318 pp. (Subsidia; 34).

PONS Y TORRES, Salvador. El clero secular filipino. Apuntes bibliográficos y biográficos. Trabajo de información dedicado a Su Santidad León XIII por el Sr. [...], presbítero europeo. (Complemento de la Defensa del Clero Filipino). Manila: Imprenta La Democracia, 1900.

\subsubsection{Clero regular}

a. Generales a todas las Ordenes

ANDRÉS MARTÍN, Melquíades (ed.). Misioneros extremeños en Hispanoamérica y Filipinas. Diccionario biográfico y bibliográfico. Madrid: Biblioteca de Autores Cristianos, 1993. 426 pp. (BAC Maior).

b. Agustinos calzados ${ }^{49}$

APARICIO LÓPEZ, Teófilo (OSA). Misioneros y colonizadores agustinos en Filipinas. Valladolid: Imprenta Agustiniana, 1965. 424 pp.

49 Puede ser útil la obra de Lazcano, Rafael. Bibliographia Missionalia Augustiniana. América Latina (1533-1993). Madrid: Ed. Revista Agustiniana, 1993. 645 pp. 
CANO, Gaspar (OSA). Catálogo de los religiosos de N.P.S. Agustín de la Provincia del Santísimo Nombre de Jesús de Filipinas, desde su establecimiento en estas Islas hasta nuestros días, con algunos datos biográficos de los mismos. Compuesto y ordenado siendo provincial... Juan J. Aragonés por [...]. Manila: Imprenta de Ramírez y Giraudier, 1864. 336 pp.

CASTRO, Agustín María de (OSA). Misioneros agustinos en el Extremo Oriente, 1565-1780 (Osario Venerable), por [...]. Edición, introducción y notas por el P. Manuel Merino, OSA. Madrid: CSIC, Instituto Santo Toribio de Mogrovejo, 1954. 518 pp. (Missionalia Hispanica; B-6).

MERINO, Manuel (OSA). Agustinos evangelizadores de Filipinas, 1565-1965. Madrid: Archivo Agustiniano, 1965. XLVIII, $582 \mathrm{pp.}$

PÉREZ, Elviro Jorde (OSA). Catálogo bio-bibliográfico de los religiosos agustinos de la Provincia del Santísimo Nombre de Jesús de las Islas Filipinas, desde su fundación hasta nuestros días. Manila: Establecimiento Tipográfico del Colegio de Santo Tomás, 1901. XVIII, 873 pp.

RODRÍGUEZ RODRÍGUEZ, Isacio (OSA) y Jesús ÁLVAREZ (OSA). Diccionario biográfico agustiniano. Provincia de Filipinas. Valladolid: Estudio Agustiniano, 1992. 2 v. Vol. I (1565-1588), 577 pp.; Vol. II (15901600), 540 pp. En curso de publicación.

c. Agustinos recoletos descalzos

SÁDABA DEL CARMEN, Francisco (ORSA). Catálogo de los religiosos Agustinos Recoletos de la Provincia de San Nicolás de Tolentino de Filipinas desde el año 1606, en que llegó la primera misión a Manila, hasta nuestros días. Dispuesto por el M.R.P. Fr. [...]. Madrid: Imprenta del Asilo de Huérfanos del Sagrado Corazón de Jesús, 1906. 885 pp.

\section{d. Dominicos}

[OCIO, Hilario María, OP]. Reseña biográfica de los religiosos de la Provincia del Santísimo Rosario de Filipinas, desde su fundación hasta nuestros días. Por un religioso de la misma Provincia. Y mandada dar a luz de orden de Nuestro M.R.P. Provincial Fr. Santiago Payá. Manila: Establecimiento Tipográfico del Real Colegio de Santo Tomás, 1891. 2 v. Vol.I (de 1587 a 1650), 526 pp. Vol.II (de 1658 a 1700), 497 pp.

[-] Compendio de la "Reseña biográfica" de los religiosos de la Provincia del Santísimo Rosario de Filipinas, desde su fundación hasta nuestros días, por el autor de la misma. Dáse a luz de orden de Nuestro Padre Provincial M.R.P. Fr. Bartolomé Alvarez del Manzano. Manila: Establecimiento Tipográfico del Real Colegio de Santo Tomás, 1895. Comprende desde 1587 a 1895. 1240 pp. más índices. 


\title{
PATRICIO HIDALGO NUCHERA Y FÉLIX MURADÁS GARCÍA
}

\author{
e. Franciscanos ${ }^{50}$
}

CRUIKSHANK, Bruce. Franciscans in the Philippines, 1578-1898. Bibliographical Catalogue. 1991. 413 h. en ordenador. ${ }^{51}$

GÓMEZ PLATERO, Eusebio (OFM). Catálogo biográfico de los religiosos franciscanos de la provincia de San Gregorio Magno de Filipinas, desde 1577 en que llegaron los primeros a Manila hasta los de nuestros días, formado por el P. Fr. [...], por mandado del M.R.P. Ministro Provincial de la misma Fr. Pedro Moya. Manila: Imprenta del Real Colegio de Santo Tomás, 1880. 813, LX pp.

HUERTA, Félix de (OFM). Estado geográfico, topográfico, estadístico, históricoreligioso de la Santa y Apostólica provincia de San Gregorio Magno, de religiosos menores descalzos de la regular y más estrecha observancia de N.S.P. San Francisco, en las Islas Filipinas. Comprende el número de religiosos, conventos, pueblos, situación de éstos, años de su fundación, tributos, almas, producciones, industrias, cosas y casos especiales de su administración espiritual, en el Archipiélago filipino, desde su fundación en el año de 1577 hasta el de 1853. Manila: Imprenta de los Amigos del País, a cargo de D.M. Sánchez, 1855. 437 pp. Una segunda edición, muy aumentada hasta el año de 1863, en Binondo: Imprenta de M. Sánchez y Compañía, 1865. 712 pp.

OLTRA PERALES, Enrique. "Diccionario biográfico de franciscanos valencianos en Filipinas". En: Idem, Franciscanos valencianos en América y Filipinas. Presentación del Cardenal Enrique y Tarancón. Valencia: Generalitat de Valencia, Consell Valencià de Cultura, 1995; pp. 215-238.

PASTRANA RIOL, Apolinar (OFM). "Franciscanos españoles repatriados con motivo de la revolución filipina de 1898". Archivo Ibero-Americano, tomo XXXV, n. 137 (Madrid, enero-marzo 1975): pp. 3-52; y tomo XXXV, n. 139 (Madrid, julio-septiembre 1975): pp. 369-404.

— "Franciscanos residentes en Filipinas al sobrevenir la revolución de 1898". Archivo Ibero-Americano, tomo XXXVII, n. 146 (Madrid, 1977): pp. 209247; y tomo XXXVIII, n. ${ }^{\circ}$ 149-152 (Madrid, 1978): pp. 647-686.

PÉREZ, Lorenzo (OFM). "Los franciscanos en el Extremo Oriente (Noticias biobibliográficas)". Archivum Franciscanum Historicum 1 (Roma, 1908): pp. 241-247 y 536-543; 2 (1909): pp. 47-62, 232-239 у 548-560; 3 (1910): pp. 39-46; 4 (1911): pp. 50-61 y 482-503.

50 Puede ser útil la obra de Castro y Castro, Manuel de (OFM). Bibliografía hispano franciscana. Santiago de Compostela: s.i., 1994. 895 pp.

51 Se trata de una nota biográfica de todos los franciscanos que estuvieron en las Filipinas. Una copia se halla en el Archivo Franciscano Ibero Oriental (AFIO), Madrid. En este mismo archivo y del mismo autor se encuentra un tomo sin título en lengua inglesa, de 935 pp. en ordenador más 13 hojas de índices. Recoge la lista de párrocos de las diferentes parroquias administradas por los franciscanos de Filipinas hasta 1898. Primero aparece la historia del pueblo y, a continuación, la lista de sus párrocos. 


\section{Diccionarios temáticos y enciclopedias}

[ALGUÉ, José. SJ]. El Archipiélago filipino. Colección de datos geográficos, estadísticos, cronológicos y científicos relativos al mismo, entresacados de anteriores obras u obtenidos con la propia observación y estudio. Por algunos Padres de la Misión de la Compañía de Jesús en estas Islas. Washington: Imprenta del Gobierno, 1900. 2 v. ill. maps. XXVI, 708 pp.; XX, 469 pp.

BLUMENTRITT, Fernando. "Diccionario mitológico de Filipinas". En: Wenceslao E. Retana, Archivo del Bibliófilo Filipino: recopilación de documentos históricos, científicos, literarios y políticos y estudios biográficos por [...]. Tomo II: pp. 337-454. Madrid: M. Minuesa de los Ríos, 1896.

- Breve diccionario etnográfico de Filipinas. Manila: Imprenta Santa Cruz, 1889. 16 pp.

— "Diccionario etnográfico de Filipinas". En: La Política de España en Filipinas, v. 7 (15 abril y 30 mayo 1897): pp. 162-167, 207-213, 237-242.

— "Diccionario de idiomas filipinos". En: La Política de España en Filipinas, v. 8 (28 febrero 1898): pp. 77-80.

BUZETA, Manuel y Felipe BRAVO. Diccionario geográfico, estadístico, histórico, de las Islas Filipinas. Madrid: Imprenta de D. José C. de la Peña, 1850. 2 v. VII, 567 pp.; $476+18$ pp.

DEMETRIO, Francisco R. (comp.). Encyclopedia of Philippine Folk Beliefs and Customs. Compiled and Edited by [...], SJ 2. ${ }^{\mathrm{a}}$ ed. enlarged and revised. Cagayán de Oro City, Philippines: Xavier University, 1991. 2 v. 702 pp.; 634 pp. Una 1. ${ }^{a}$ ed. en 1970. 4 v. XXXVI, 992 pp.

GALANG, Zoilo M. (ed.). Encyclopedia of the Philippines. 3. ${ }^{\mathrm{a}}$ ed. Manila: Exequiel Floro, 1950-1958. $20 \mathrm{v} .^{52}$ Una 1. ${ }^{\mathrm{a}}$ ed. en Manila: Philippine Education Co., 1935-1936. 10 v.

GUILlERMO, Artemio R. y May Kyi WIN. Historical Dictionary of the Philippines. Lanham, Md.: The Scarecrow Press, 1997. XL, 363 pp.

LOPE Y VERGARA, Félix. Diccionario alfabético legislativo del comercio de Filipinas y Nueva España. Estudio introductorio y notas, Ramón Sánchez Flores. México: Universidad Nacional Autónoma de México, Instituto de Investigaciones Jurídicas, 1981. 148 pp. (Serie A. Fuentes. b) Textos y estudios legislativos; 29).

MARING, Ester G. y Joel M. MARING. Historical and Cultural Dictionary of the Philippines. Metuchen, New Jersey: Scarecrow Press, 1973. VII, 240 pp. (Historical and Cultural Dictionaries of Asia Series; 3).

52 v. 1-2, Literature; 3-4, Biography; 5-6, Commerce and industry; 7-8, Art; 9, Education; 10, Religion; 11-12, Government and politics; 13-14, Science; 15-16, History; 17-18, Builders; 19-20, General Information. 
PAN, José Felipe del. Diccionario de la administración, del comercio y de la vida práctica en Filipinas, por D. [...], con la colaboración de D. Juan de la Rosa. Tomo I [letras A-Con]. Manila: Manuel Pérez, 1879. 728 pp.

PHILIPPINE Encyclopedia of the Social Sciences. Quezon City: Philippine Social Science Council, 1993. 2 v.

ROCES, Alfredo R. (editor in Chief); Gilda CORDERO-FERNANDO y Carlos QUIRINO (associate editors); Manuel C. GUTIERREZ (sub-editor). Filipino Heritage. The Making of a Nation. [Manila?]: Lahing Philipino Publishing Inc., c.1977-c.1978. 10 v. 2772 pp. ill.

RODRÍGUEZ BERRIZ, Miguel. Diccionario de la Administración de Filipinas. Por [...], Jefe letrado de la Administración Central de Rentas, Propiedades y Aduanas. Manila: Establecimiento Tipo-Litográfico de M. Pérez (Hijo), 1887-1888. 17 v. $^{53}$

TIBÓN, Gutierre. Diccionario etimológico comparado de los apellidos españoles, hispanoamericanos y filipinos. México: Fondo de Cultura Económica, 1992. 433 pp. Una 1. ${ }^{a}$ ed. en México: Diana, 1988.

UNITED STATES. BUREAU OF INSULAR AFFAIRS. A Pronouncing Gazetteer and Geographical Dictionary of The Philippine Islands, United States of America, with Maps, Charts and Illustrations. Also The Law of Civil Government in the Philippine Islands passed by Congress and Approved by the President, July 1, 1902. With a Complete Index. Prepared in the Bureau of Insular Affairs, War Department. 1902 (September 30, 1902). Washington: Government Printing Office, 1902. XXXIX, 933 pp. maps.

\section{Bibliografía lingüística ${ }^{54}$}

ASUNCION-LANDE, Nobleza C. A Bibliography of Philippine Linguistics. Athens, Ohio: Ohio University, Center for Internacional Studies, Southeast Asia Program, 1971. XXIII, 147 pp. (Papers in International Studies. Southeast Asia Series; 20).

BERNARDO, Gabriel A. A Bibliography of the Old Philippine Syllabaries. (A Paper presented at the Joint Meeting of the Fourth Far-Eastern Prehistoric Congress and Anthropology Division of the Eigth Pacific Science Congress, Held at Quezon City, Philippines, November 16 to 28, 1953). Quezon City: University of Philippines, The Library, 1953. 52 h. Mecanografiado.

53 El último es un apéndice a los volúmenes I y II. Hay que añadir los apéndices de los años 1888 a 1892 (publicados de 1889 a 1893). 6 v. Nueva edición, Manila: 1893. 2 v., letras A-C. Indices cronológico y alfabético de todas las disposiciones comprendidas en la primera edición.

54 Vid. además Yabes, Leopoldo Y. y José Resurrección CALIP (comps.) en el epígrafe 1.2. 
BLAKE, Frank R. "A Bibliography of the Philippine Languages. Part 1". Journal of the American Oriental Society 40 (1920): pp. 25-70.

MACHADO, Kit; Richard HOOLEY; Lawrence A. REID. Philippine Studies: Political Science, Economics and Linguistics. Donn V. Hart, editor. Detroit, Michigan: Northern Illinois University, Center for Southeast Asian Studies, 1981. IX, 290 pp.

SILGO GAUCHE, Luis. "Fuentes para el estudio de 'Baybayin', escritura prehispánica filipina". En: Francisco de Solano y otros (eds.), Extremo Oriente ibérico; pp. 257-267.

SPIECKER-SALAZAR, Marlies. "A Contribution to Asian Historiography: European Studies of Philippine Languages from 17th to the 20th Century". Archipel 44 (París, 1992): pp. 183-202.

WARD, Jack H. A Bibliography of Philippine Linguistics and Minor Languages. With Annotations and Indices Based on Works in the Library of Cornell University. Ithaca, New York: Cornell University, Department of Asian Studies, 1971. VIII, 549 pp. (Southeast Asia Program. Data Paper; 83. Linguistics Series; 5).

WELSH, Doris Varner (comp.). Checklist of Philippine Linguistics in the Newberry Library. Chicago, Illinois: The Newberry Library, 1950. VI, $176 \mathrm{pp}$.

\subsection{Diccionarios lingüísticos (mínima selección)}

CUADRADO MUÑIZ, Adolfo. Hispanismos en el tagalo. Diccionario de vocablos de origen español vigentes en esta lengua filipina. Revisado por Antonio M. Molina. Estudio preliminar de Rodolfo Barón Castro. Madrid: Oficina de Educación Iberoamericana, Servicio de Información y Publicaciones, 1972. 632 pp. (El idioma español en el mundo; 2).

RETANA Y GAMBOA, Wenceslao Emilio. "Diccionario de Filipinismos, con la revisión de lo que al respecto lleva publicado la Real Academia Española". Revue Hispanique, tomo LI, n. ${ }^{\circ} 119$ (New York y París, febrero 1921): pp. 1-174.

SERRANO LAKTAW, Pedro. Diccionario Hispano-Tagálog. Primera parte. Manila: Establecimiento Tipográfico "La Opinión”, a cargo de G. Bautista, 1889.

- Diccionario Tagálog-Hispano. Segunda parte. Manila: Imprenta y Litografía de Santos y Bernal, $1914 .^{55}$

55 Las dos partes del diccionario han sido reproducidas facsimilarmente en Madrid: Ediciones Cultura Hispánica, 1965. 3 v. 